\title{
Dinosaur tracks from the Langenberg Quarry (Late Jurassic, Germany) reconstructed with historical photogrammetry: Evidence for large theropods soon after insular dwarfism
}

\author{
Jens N. Lallensack, P. Martin Sander, Nils Knötschke, and Oliver Wings
}

\begin{abstract}
Here we describe dinosaur tracks from the Langenberg Quarry near Goslar (Lower Saxony) that represent the first footprints from the Late Jurassic of Germany discovered outside the Wiehen Mountains. The footprints are preserved in Kimmeridgian marginal marine carbonates. They vary in length from 36 to $47 \mathrm{~cm}$ and were made by theropod dinosaurs. The original tracksite with 20 footprints was destroyed by quarrying soon after its discovery in 2003. Only the five best defined footprints were excavated. Based on scanned-in analog photographs which were taken during the excavation, a three-dimensional (3-D) model of the original tracksite was generated by applying historical photogrammetry. The resulting model is accurate enough to allow a detailed description of the original tracksite. Different preservation types result from changing substrate properties and include both well-defined footprints and deeply impressed footprints with elongated heel and variably defined digit impressions. The tracksite was discovered stratigraphically close to the bone accumulation of the dwarfed sauropod dinosaur Europasaurus holgeri and probably records a sea level fall along with a faunal interchange, which would likely have eliminated the resident dwarf island fauna. The two largest and best preserved footprints differ from most other Late Jurassic theropod footprints in their great width. Two different trackmaker species might have been present at the site. Several hypotheses presented in a recent paper on Late Jurassic dinosaur tracks from the Wiehen Mountains by Diedrich (2011b) are commented upon herein.
\end{abstract}

Jens N. Lallensack. Steinmann-Institut für Geologie, Mineralogie und Paläontologie, Universität Bonn, Nussallee 8, 53115 Bonn, Germany. jens.lallensack@uni-bonn.de;

P. Martin Sander. Steinmann-Institut für Geologie, Mineralogie und Paläontologie, Universität Bonn, Nussallee 8, 53115 Bonn, Germany.m.sander@uni-bonn.de

Nils Knötschke. Dinosaurier-Freilichtmuseum Münchehagen, Alte Zollstrasse 5, 31547 Rehburg-Loccum, Germany.n.knoetschke@dinopark.de

Oliver Wings. Landesmuseum Hannover, Willy-Brandt-Allee 5, 30169 Hannover, Germany \& Museum für Naturkunde Berlin, Invalidenstraße 43, 10115 Berlin, Germany. dr.wings@gmail.com

PE Article Number: 18.2.31A

Copyright: Palaeontological Association May 2015

Submission: 12 December 2014. Acceptance: 12 April 2015

Lallensack, Jens N., Sander, P. Martin, Knötschke, Nils, and Wings, Oliver. 2015. Dinosaur tracks from the Langenberg Quarry (Late Jurassic, Germany) reconstructed with historical photogrammetry: Evidence for large theropods soon after insular dwarfism.

Palaeontologia Electronica 18.2.31A: 1-34

palaeo-electronica.org/content/2015/1166-langenberg-tracks 
Keywords: Late Jurassic, dinosaur tracks, Theropoda, insular dwarfism, photogrammetry

\section{INTRODUCTION}

The last decade saw a huge increase of the Late Jurassic Central European dinosaur track record, with now over 50 tracksites being documented in the literature. In Central Europe, five main track-bearing regions may be recognized, including the Swiss Jura Mountains, the French Jura Mountains, Lot (France), the Polish Holy Cross Mountains, and the German Wiehen Mountains (northeastern North-Rhine Westphalia) (Figure 1.1). Most sites are known from the Swiss Jura Mountains; these sites have been estimated to encompass at least 17,000 individual footprints (Marty et al., 2013). Despite large areas of exposures of Late Jurassic sediments, dinosaur tracks from this period remain rare in Germany. All three previously published tracksites are located in the Wiehen Mountains, including the famous Barkhausen tracksite which has been known since 1921
(Kaever and de Lapparent, 1974) as well as two quarries that have produced isolated footprintbearing slabs (Diedrich, 2011b).

In 2003, an additional tracksite comprising over 20 footprints was discovered by private fossil collector Holger Lüdtke in the Langenberg Quarry near Goslar (Lower Saxony), stratigraphically only some $5 \mathrm{~m}$ above the bed that contained the bones of the well-known dwarf sauropod Europasaurus (Sander et al., 2006; Carballido and Sander, 2013; Marpmann et al., 2014). These are the first Late Jurassic footprints from Germany located outside the Wiehen Mountains (Figure 1.1) and the first being preserved in carbonates in Germany. The tracksite is also of paleogeographic importance, as it provides evidence for the earliest known emersion event in the Langenberg section. This sea level fall allowed the immigration of large theropods - as recorded by the Langenberg tracks -
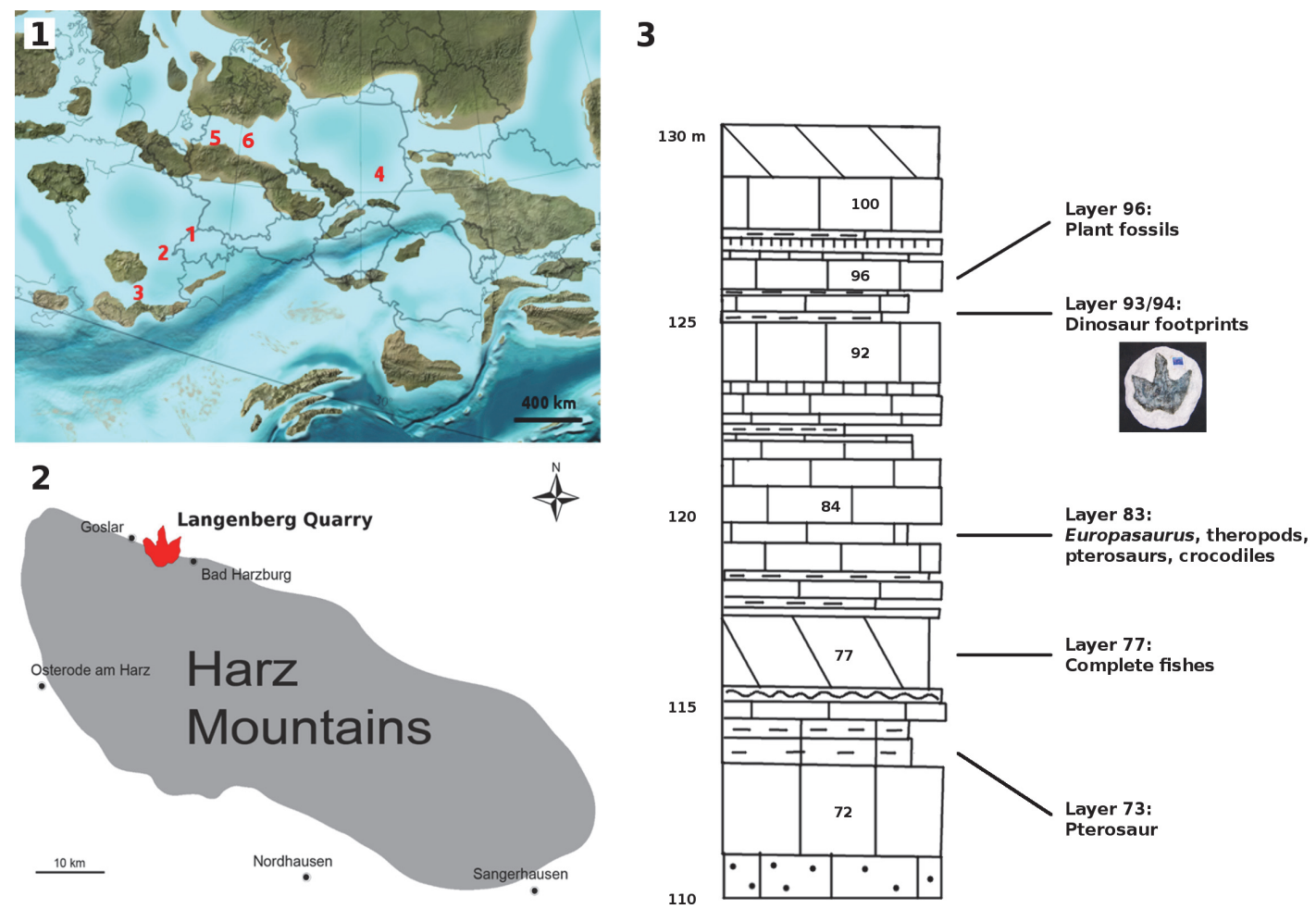

FIGURE 1. Location and stratigraphy of the Langenberg locality. 1: Paleogeographic map of the Late Jurassic (150 Mya) of Central Europe, showing the five main regions which contain dinosaur tracks: (1) Swiss Jura Mountains; (2) French Jura Mountains; (3) Lot (France); (4) Holy Cross Mountains (Poland); (5) Wiehen Mountains (Germany) as well as the Langenberg tracksite (6), which is described herein. Map reconstruction from Ron Blakey, Colorado Plateau Geosystems, Arizona, USA (cpgeosystems.com/paleomaps.html). 2: Geographical position of the Langenberg Quarry near Goslar. 3: Measured section of a part of the "Mittlerer Kimmeridge", redrawn from Fischer (1991). 


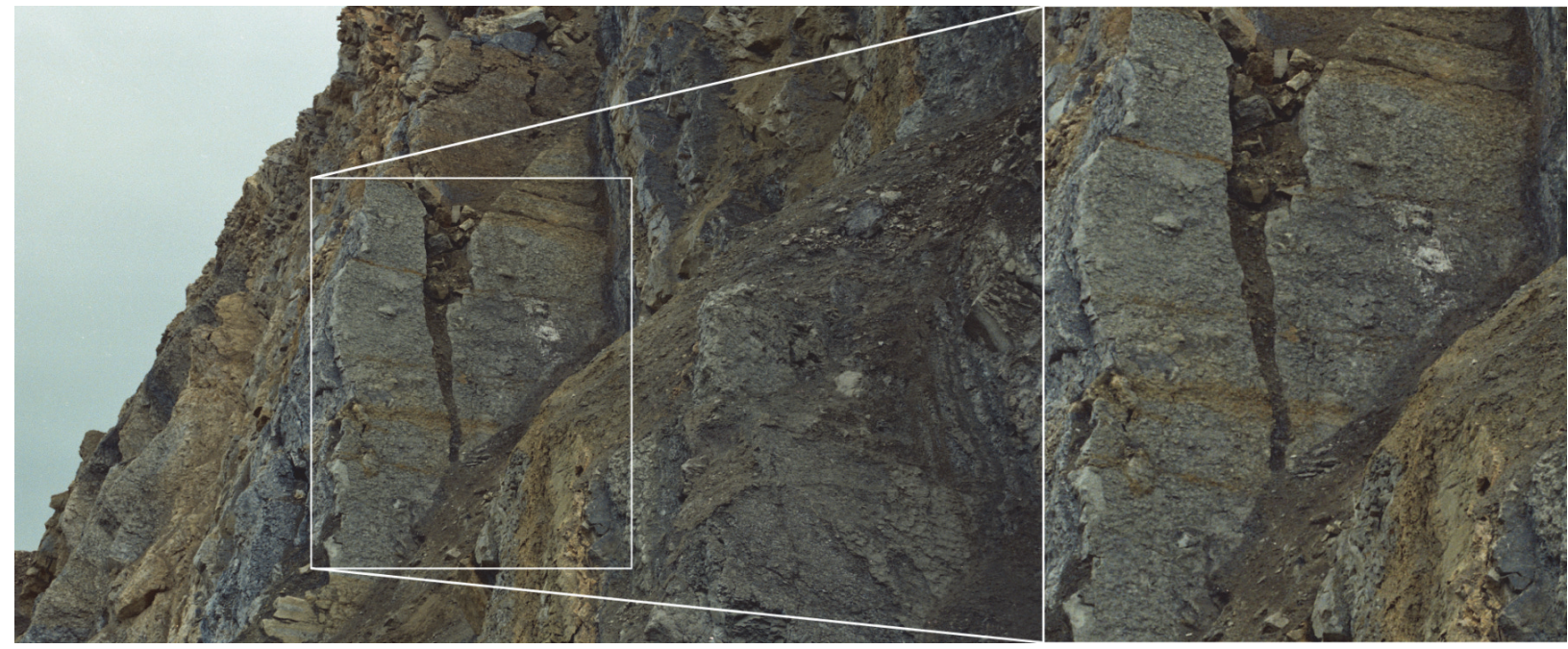

FIGURE 2. The Langenberg tracksite during excavation. Left: Archival photograph by NK (2003). The white box shows the location of the tracksite. Right: Digitally cropped version of the photograph, showing the tracksite (the whitish spot on the right slab represents plaster). See also Figure 9 for depth-color images of the photogrammetric model and Figure 10 for an orthofoto and an interpretative drawing.

with presumably fatal consequences for a specialized, dwarfed island fauna.

The Langenberg footprints are preserved as natural casts on an overturned, steeply inclined bed, which is divided by a longitudinal fissure. When discovered on May 22, 2003, several footprints already had fallen down from the slab. An emergency excavation was carried out the next day by Holger Lüdtke and one of us (NK), resulting in the recovery of the five best preserved footprints. Soon after, the original tracksite was destroyed by quarrying. Although three freehand drawn field sketches including approximate distances between individual footprints have been recorded, this data is partly contradictory and thus could not be used for our study. Fortunately, the tracksite and parts of the excavation process were documented with 57 analog color negative photographs. These photographs served as the basis for a historical photogrammetric model of the site.

\section{LOCALITY, GEOLOGY, AND STRATIGRAPHY}

The quarry, which is actively quarried, including the use of explosives, is located at the northern rim of the Harz Mountains between Goslar and Bad Harzburg in Lower Saxony, Germany (Figure 1.2). To the south, the Mesozoic sedimentary rocks are separated from the Harz Block by the Northern Harz Boundary Fault. Due to the uplift of the Harz Mountains along this fault, the adjacent sedimentary beds were dragged upwards, resulting in a steep inclination or, as seen in the Langenberg
Quarry, even overturned positions (Fischer, 1991). In the Langenberg Quarry, the overturned beds dip with approximately $70^{\circ}$ towards the south; thus, when seen from the south, the undersides of the beds are visible (Figure 2) (Fischer, 1991).

The active part of the large Langenberg Quarry is divided into three levels, each with a $>20$ $\mathrm{m}$ high face. The footprints were found in the middle quarry face at the approximate coordinates $\mathrm{N}$ $51^{\circ} 54^{\prime} 6.74 "$, E $10^{\circ} 30^{\prime} 27.73 "$. The sediments are mostly composed of carbonates with intercalated mudstones and marls deposited in a shallow sea with varying water depths and salinity (Fischer, 1991; Thies and Mudroch, 1996). Stratigraphically, the track casts belong to bed 94 of Fischer (1991), only about $5 \mathrm{~m}$ above bed 83 , which so far has yielded the remains of at least 20 individuals of the dwarfed basal macronarian sauropod dinosaur Europasaurus holgeri (Sander et al., 2006; Carballido and Sander, 2013; Marpmann et al., 2015) (Figure 1.3).

The exact temporal extent in the Late Jurassic of the Langenberg section is unclear, as ammonites are extremely rare (Fischer, 1991). Traditionally, the section is divided into the regional lithostratigraphic units "Korallenoolith" and "Kimmeridge" (Fischer, 1991; Pape, 1970). The "Kimmeridge" of northwestern Germany is not identical with the Kimmeridgian of the international chronostratigraphic time scale (Schweigert, 1999). It is divided into a lower unit, the "Unterer Kimmeridge"; a middle unit, the "Mittlerer Kimmeridge"; and an upper unit, the "Oberer Kimmeridge" (Fischer, 


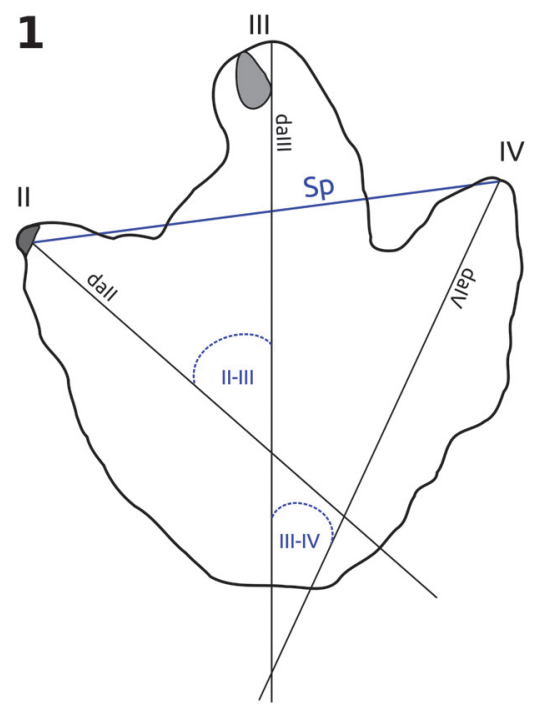

3
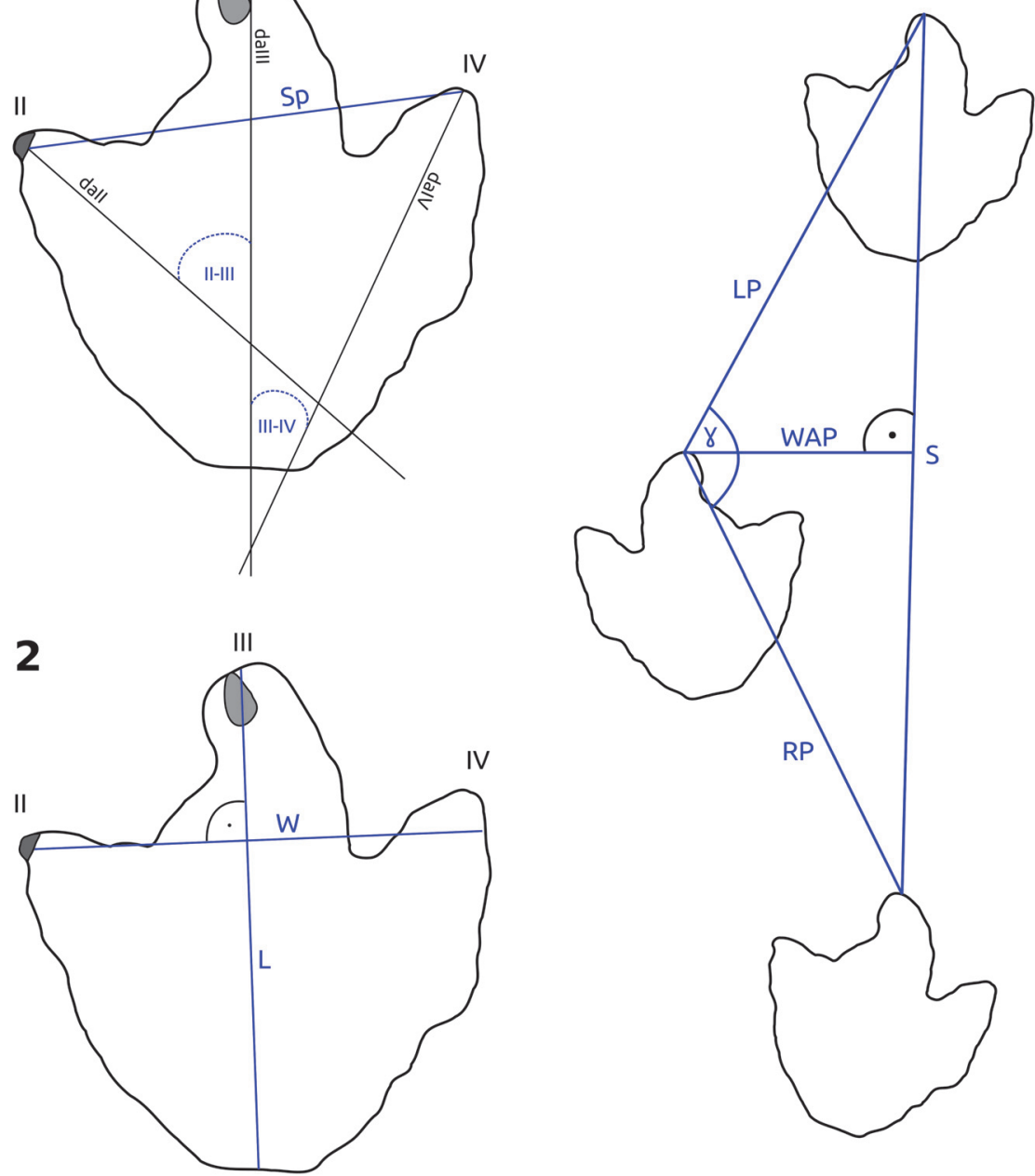

FIGURE 3. Schematic outline drawings (based on footprint DFMMh/FV 644 from the Langenberg tracksite) showing basic footprint and trackway parameters, measured lines and angles are highlighted in blue. Gray areas indicate claw marks. 1: Digit divarication, measured in degrees between the digital axes (da) of digit II and III and III and IV. The footprint span (Sp) was measured between the distal ends of the axes of digit impressions II and IV. 2: Footprint length and width. Footprint width was measured at a right angle to the digital axis of digit III. 3: Basic trackway parameters following Marty (2008) (RP: right pes; LP: left pes; S: stride length; WAP: Width of the pes angulation pattern; $\mathrm{Y}$ : pace angulation).

1991; Pape, 1970). Both Europasaurus and the tracks described herein pertain to the "Mittlerer Kimmeridge", which in the Langenberg Quarry reaches a thickness of ca. $55 \mathrm{~m}$ and is dominated by limestone beds with thinner, intercalating marl beds (Figure 1.3) (Fischer, 1991). Based on ammonite finds, the northwest-German "Mittlerer Kimmeridge" has been shown to represent the lower part of the upper Kimmeridgian of the international chronostratigraphic time scale (Schweigert, 1999). Thies et al. (2007) suggested that most of the Langenberg section (beds 36 to 153) falls within the mutabilis ammonite zone. In this case, the mutabilis ammonite zone in the Langenberg Quarry would have reached a thickness of 75 $m$ (Thies et al., 2007). According to Hardenbol et al. (1998), the mutabilis ammonite zone represents 520,000 years. The dinosaur tracks are separated from the Europasaurus bones by approximately 5 $\mathrm{m}$. Thus, assuming a constant sedimentation rate, the time span between Europasaurus and the dinosaur tracks would have been as short as 35,000 years.

The stratigraphy of the Langenberg Quarry was described and subdivided by Pape (1970) into 192 separate beds. Two more recent, but partially 
different subdivisions were provided by Zihrul (1990) and Fischer (1991), leading to some confusion. Here the stratigraphic subdivision of Fischer (1991) is employed. Note that the abundant Europasaurus remains were found in bed 83 , not in bed 93 as was accidently stated in several recent papers (Sander et al., 2006; Carballido and Sander, 2013; Marpmann et al., 2015).

The footprint casts were found on the underside of bed 94, which, according to the section published by Fischer (1991), is a limestone measuring ca. $40 \mathrm{~cm}$ in thickness (Figure 1.3). Bed 94 is bioturbated and contained turtle shell fragments beneath one of the footprint casts. One cast of a single digit impression, whose original location on the slab is unknown, was cut and polished, revealing a gastropod rich biomicrite (Appendix 1). Bioclasts are visible on the surface of all preserved footprint casts, including fragments of oyster shells larger than $1 \mathrm{~cm}$ in diameter. The track layer, the upper surface of which is the surface on which the animals walked, and thus the bed that contained the original footprint molds, is bed 93 . This bed is a marl bed somewhat thinner than bed 94 (Fischer, 1991). At the time of discovery of the tracksite, this marl has already been eroded away, exposing the natural casts (Figure 2).

\section{MATERIAL AND METHODS}

\section{Material, Data Acquisition and Terminology}

Five natural casts (positive hyporeliefs) of tridactyl dinosaur tracks are described. The specimens are stored in the collection of the Dinosaurier-Freilichtmuseum Münchehagen (specimen numbers DFMMh/FV 644-648). Threedimensional models and orthophotos of each specimen were generated based on digital photographs taken with a Canon EOS 550D DSLR camera and a Canon EF $20 \mathrm{~mm}$ f/2.8 lens in the photogrammetric software Agisoft Photoscan Professional v.1.0.4. (www.agisoft.ru/products/photoscan/professional/). Depth-color images of the 3-D models were generated using the free software Paraview (www.paraview.org/), relative to a horizontal plane which was defined by markers set onto the surface of the model in Agisoft Photoscan. A general discussion on orthophoto generation can be found in Rau et al. (2002), while the photogrammetric procedures are discussed in Falkingham (2012) and Mallison and Wings (2014). Measurements were taken software-based on the digital models using Agisoft Photoscan and on A4 print-outs of topview orthophotos. Photogrammetric 3-D models are pro- vided in the supplementary material (Appendix 28).

The original tracksite in the Langenberg Quarry is no longer preserved. Although the bed is still exposed in the quarry, quarrying proceeds along strike, exposing the beds only in cross section and not along bedding planes, making additional potential trackways difficult to detect. Fieldwork documentation consists of 57 analog photographs and three field sketches that contain some distances between individual tracks. Because the sketches had to be created in a hurry, there are inaccuracies and sometimes contradictory information as well as a lack of important trackway parameters (i.e., stride length and pace angulation). Therefore, a photogrammetric reconstruction of the whole site was carried out. Even though the field photographs were not intended for photogrammetric purposes, the generation of a relatively accurate model was possible, allowing the generation of a site map, the recognition of features not well seen on the photographs (e.g., slight elevations of the slab surface), and even precise measurements. The procedure, a so-called "historical" or "archival" photogrammetry (Chandler and Clark, 1992; Falkingham et al., 2014), is elaborated upon below. Unfortunately, two of the salvaged footprints (DFMMh 646 and 648) were not recorded on the field sketches or on photographs; their original position thus remains unknown.

The terminology used in this work follows Thulborn (1990) and Marty (2008). The term "deep track" is used according to Gatesy (2003), referring to deeply impressed tracks produced by trackmakers sinking deeply into soft mud. The term "heel" is used here to refer to the posterior part of the footprints, which in theropods usually was impressed by the distal part of the metatarsus but not by the much more proximally located anatomical heel.

Measurements are taken according to Marty (2008) and as indicated in Figure 3. Track dimensions were measured excluding claw marks. Track length includes the "heel" impression (if present). The interdigital angles are measured between the digital axes, which divide each digit into two approximately even-sized halves. Using this definition, the digital axes normally do not intersect at a single point (Marty, 2008). The footprint span was measured between the distal ends of the axes of digit impressions II and IV and thus is not identical with the footprint width, which was measured perpendicular to the axis of digit impression III. Pace length usually is measured between the tips of digit impression III of two consecutive tracks. Because 
digit impressions are poorly preserved in deep tracks, pace length was measured between the midpoints of a line connecting the two hypexes. The orientations of the footprints and trackways are given as seen in the quarry. Being located on an overturned slab, tracks oriented towards the north originally would have been oriented towards the south; thus, the given directions do not represent the original walking directions of the animals. The descriptions of the individual excavated footprints are ordered by specimen number, while the descriptions of the trackways are ordered based on their position on the slab from the left to the right. For reasons of clarity, the interpretation of the tracks and trackways is given directly after their respective description.

\section{Historical Photogrammetry}

Historical or archival photogrammetry describes the derivation of spatial data from historical or archival analog photographs, allowing the three-dimensional reconstruction of objects that no longer exist (Chandler and Clark, 1992). This method was first applied in 1989 to reconstruct the Black Ven landslide in Dorset (Chandler and Cooper, 1989), and since then found diverse uses in research and commercial projects (e.g., Chandler and Clark, 1992; Fox and Cooper, 1998; Wiedemann et al., 2000). Until recently, photogrammetry only allowed measurements between single points, which were manually identified on two or more photographs (Matthews and Breithaupt, 2001). Only with the fast advance of photogrammetric software in recent years, the automatic generation and measurement of whole point clouds containing thousands of points became possible (Matthews, 2008). The potential of modern photogrammetric software to generate detailed three-dimensional models based on scanned-in archival photographs of dinosaur tracks was recently demonstrated by Falkingham et al. (2014), who were able to derive and analyze a three-dimensional model of the wellknown Lower Cretaceous Paluxy River tracksite in Texas based on photographs taken in 1940. Since the exact procedure was not outlined by these authors, a detailed description of our approach is provided below. The commercial software Agisoft Photoscan Professional v. 1.04 was used, although free alternatives are available and have been shown to be suitable for historical photogrammetry (Falkingham, 2012; Falkingham et al., 2014). Due to the progressive advancement of photogrammetric software, parts of the recommendations given below probably will become obsolete in the near future.

Several factors may adversely affect photogrammetric results when using archived analog photographs. In case of the Langenberg tracksite, the number of images taken from different angles is small, and detail photographs are available only for a part of the site, resulting in pronounced spatial variation in resolution of the final model. Some detail photographs could not be aligned due to poor overlap with other photographs. While the photogrammetric software requires that the object of interest does not change between photographs, the Langenberg tracksite photographs document various stages of the excavation process. The photographs variably include buckets, meter sticks, plaster residues, and humans (i.e., objects that appear repeatedly but move in relation to the tracks), while footprints are exposed in some photographs but are removed or covered in plaster in others. Artifacts on the negatives like scratches and dust grains can alter the film material during storage, and additional artifacts and distortion may be introduced during the scanning process. Last but not least, metadata for the analog photographs, most importantly the focal length, are unknown and have to be calculated by the software.

A total of 57 photographs of the original tracksite was taken by Holger Lüdtke and one of us (NK), using two separate cameras. In the final model, 41 of these photographs were aligned. Because the trackway layer was steeply inclined, most photographs were taken from the base of the slab at a low angle, affecting the quality of the model especially in the upper parts of the slab. Thus, several individual prints in the model lack sufficient resolution on their upper sides, and four tracks originally noted during the excavation on the very top of the left slab are not discernible in the photogrammetric model.

The photogrammetric model was scaled using two meter sticks present on the photographs, the first located on the left slab along trackway 1 , and the second located on the right slab next to DFMMh/FV 644. Both meter sticks, respectively, are present in the same position on more than one photograph, allowing a precise scaling. For each meter stick, two scale bars were created, and the camera alignment was optimized afterwards, following the procedure outlined in Mallison and Wings (2014). The highest precision is only reached in areas close to the meter sticks and is decreasing considerably on areas which are more poorly resolved. Footprints located well away from 
the camera positions are the most poorly resolved; their depth is significantly underestimated in the model. Distances noted during fieldwork concur with measurements taken from the historical photogrammetric model. To further validate the accuracy of measurements based on the historical photogrammetric model, several measurements of the footprints DFMMh 644 and 646 were taken both on the high-accuracy photogrammetric models of the excavated casts and on the historical photogrammetric model which shows these footprints in situ. For three independent measurements taken on DFMMh 644 , an error of $0.03 \%, 1.64 \%$, and -0.64 $\%$ was determined. This footprint was located near the meter stick that was used for scaling on the right slab, and the observed error is probably mostly caused by the inevitably imprecise placement of measuring points given the poor resolution of the historical photogrammetric model. However, for three independent measurements taken on DFMMh 646, the observed errors are significantly higher, accounting for $6.21 \%, 4.16 \%$, and $4.63 \%$. This footprint is located in a poorer resolved area of the model, approximately $1.8 \mathrm{~m}$ away from the closest meter stick. The measured errors suggest that the size of this footprint, as well as all distances measured nearby, are systematically overestimated in the historical photogrammetric model.

DFMMh/FV 647, situated on the lowermost part of the left slab, is documented by three detail photographs (Figure 4.1-3), but, being the first footprint excavated, is not visible on most overview photographs. Since DFMMh/FV 647 appears blurry on both available overview photographs that show this footprint in situ, the detail photographs could not be aligned with the other images. Therefore, a separate model of DFMMh/FV 647 was built (Figure 4.4; Appendix 8), based only on the three detail photographs, which is the minimum number of images required by Agisoft Photoscan for a successful alignment. Two of these three images are near-identical, differing only through a slight shift of the position of the camera (Figure 4.2-3). Improved with two manually added markers, this approach resulted in a useful model allowing the recognition of additional parts of the footprint (most importantly the impression of digit II) that seemingly was lost during excavation (Figure 4.4). Footprint 14 , on the other hand, was discernible neither on the three-dimensional model nor on the orthophoto. This footprint on most photographs appears very blurry, shows a poor resolution, and is seen exclusively from a very low angle (Figure 4.5). Nevertheless, the approximate position and width of this footprint was determined by measuring the position of markers that were placed on all photographs where this footprint can be seen.

Procedure. The original negatives, measuring $36 \times 24 \mathrm{~mm}$ in physical size, were scanned at a resolution of 4800 dpi using an Epson Perfection V750 Pro flatbed photo scanner. High resolution scans are crucial not only to allow the software to find more points, but also to enable a precise manual placement of marker points on the photographs. Dust particles adhering on the film material were removed using film material cleaning cannulas. Air compressors should not be used for this task because tiny drops of oil can be introduced on the films. Since touching the film surfaces sometimes is unavoidable when handling negatives, wearing cotton gloves prevents fingerprints on valuable film material.

During scanning, the automatic cropping and color correction provided by the scanner software was turned off. Color balance and contrast was adjusted manually with the same parameters applied to every photograph using the batch mode of standard image editing programs. If necessary for the final model texture, an automatic color correction can be run after building the 3-D model just before building the texture. Importantly, all images then were cropped to exactly the same pixel dimensions, which were determined to a value slightly smaller than the smallest image in the set. Without the same dimensions, the calibration group feature in Agisoft Photoscan (see below) cannot be used.

After digital preprocessing of the images, additional editing was carried out with Agisoft Photoscan. First, all objects that were not stationary between images as well as the sky and background landscape were masked using the mask function. Masked objects will no longer interfere with the photogrammetric alignment, but can cause holes in the final model when the masked region is not visible in enough other photographs. A meter stick placed on the lower part of the left slab was not masked, since it was present on most detail shots of the region and was not moved between shots. Second, camera calibration groups were adjusted. These groups accommodate pictures that were shot with the same camera, lens and focal length (Agisoft LLC, 2014). Since the focal length is unknown, any calibration groups automatically compiled by the software were split using the "split group" command. It is advisable to keep all images separate, because the model may fail to build due to even a single incorrect grouping. How- 

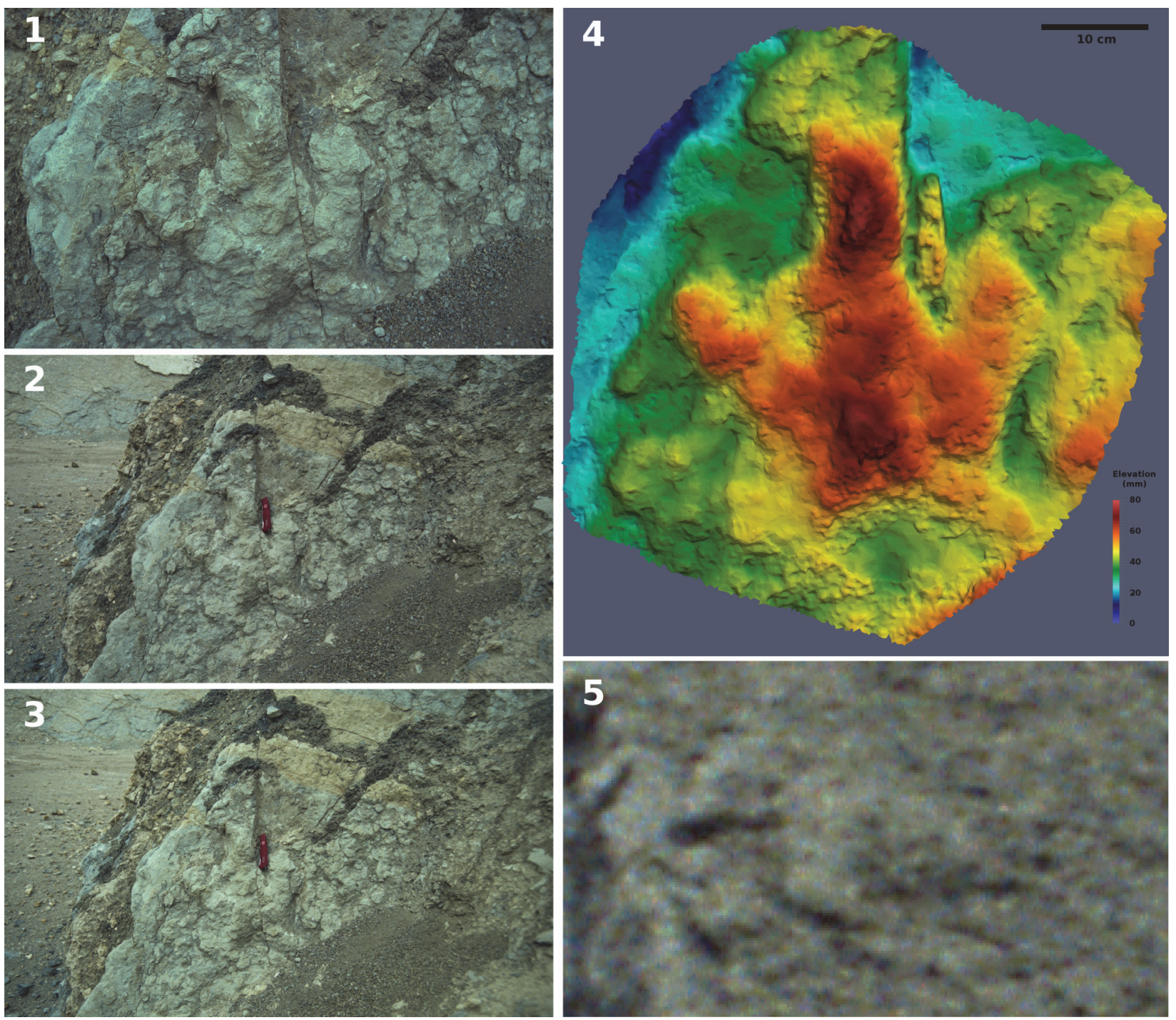

FIGURE 4. Historical photogrammetry based on photographs of limited quality. Footprints 14 and DFMMh/FV 647 are only visible on very few archival photographs and thus do not appear in the photogrammetric model of the whole tracksite. 1-3: The only three detail photographs showing DFMMh/FV 647 in situ. Note that photographs 2 and 3 are nearly identical. Photograph 1 was taken by NK, while photographs 2 and 3 were taken by Holger Lüdtke at the time of excavation in 2003. 4: Photogrammetric model (depth-color image) of DFMMh/FV 647, based only on the three detail photographs (1-3), the minimum number of photographs required by the software to generate a model. This model reveals additional details (most importantly the impression of digit II), which were lost during excavation of the footprint. 5: Detail of the best photograph showing footprint 14 (digitally cropped version of an original archival photograph by NK from 2003). Note the poor resolution and the low angle of the photograph. The approximate position and width of this footprint was determined by placing marker points on the photographs and using the camera alignment performed by Agisoft Photoscan to project these marker points on the 3D model.

ever, in the present photogrammetric model, calibration groups were created for two pairs of near identical overview images that undoubtedly were taken using the same focal length, leading to an improved overall quality of the model. Images in upright format have to be kept in separate calibration groups from images in landscape format, so neither set of images may be rotated to fit the other. Third, the focal length of the photographs was estimated. When not available through EXIF metadata, Agisoft Photoscan assumes a focal length of $50 \mathrm{~mm}$ as an initial guess, which then is automatically adjusted for each photograph during camera alignment (Agisoft LLC, 2014). Using the $50 \mathrm{~mm}$ guess worked well for photographs taken with the first camera, while photographs taken with 
the second camera failed to produce any models because the differences between the initial guess and the unknown correct values apparently were too high. To estimate the best-fit values for photographs taken with the second camera, several low quality alignment tests were run with a subset of the images testing different values for the focal length. The value which produced the most detailed model was applied to every image taken with the second camera.

When the images did not align, manual placement of markers on individual images was necessary. Ideal marker points are features that can be identified precisely and, ideally, pixel-accurately on separate images representing different angles of view, both on close-ups and overview-images. Markers are recognized as valid matches between images by the software. Additional markers can help to further improve poor-quality areas in a successfully built model. Although the alignment of all suitable photographs was possible without setting markers, four markers placed in selected areas significantly improved the resolution of our model.

The selection of images chosen for alignment usually has a significant impact on the final model. In a conventional photogrammetric reconstruction, near-identical as well as blurred images normally should be avoided as these images may introduce errors and degrade the overall quality of the model (Mallison and Wings, 2014). When attempting a historical photogrammetry, the inclusion of such pictures may be necessary when the available film material is limited and requires experimentation.

Finally, it is important to ensure the correctness of the model. Historical photogrammetry is especially susceptible to errors in camera alignment. An inaccurate camera alignment can sometimes still produce a detailed model, which may however contain severe artifacts. Such artifacts can be difficult to distinguish from real features of the object and may resemble ripple marks or cracks which, in the worst case, can lead to misinterpretations (Figure 5). To test the accuracy of camera alignment, test markers were placed. If a marker is placed on two of the images, Agisoft Photoscan estimates the position of this marker on all other images based on the previously calculated camera alignment. By reviewing these estimated marker positions and their deviation from the position of the manually placed marker, it is possible to estimate the alignment error in pixels for each image.

\section{Institutional Abbreviations}

DFMMh/FV - Dinosaurier-Freilichtmuseum Münchehagen/Verein zur Förderung der Niedersächsischen Paläontologie e.V., Rehburg-Loccum, OT Münchehagen, Germany.

\section{DESCRIPTION OF RECOVERED FOOTPRINTS}

\section{DFMMh/FV 644}

DFMMh/FV 644 (Figure 6; Appendix 3; Table 1 ) is one of the two largest imprints. The excavated cast measures $54.0 \mathrm{~cm}$ in length, which might be an overestimation since the posteriormost part probably does not belong to the actual footprint. This suspicion could be confirmed by analyzing the historical photogrammetric model which shows this footprint in situ. The minimum length of the footprint, as measured both on the excavated cast and on the historical photogrammetric model, is 46.0 $\mathrm{cm}$. The width of the footprint is $52.0 \mathrm{~cm}$. Despite its size, the footprint is relatively shallow with a maximum depth of $9.3 \mathrm{~cm}$. Digit impression III is distinctly curved to the left over its whole length. Since such curvature is usually pointing to the medial side in tridactyl dinosaur tracks (Thulborn,1990), and since the footprint is preserved as a natural cast and thus is inverted in relation to its original natural mold, it probably is a left footprint. The hypex between digit impressions II and III forms a broad semicircle, while the hypex between digits III and IV is V-shaped. Digit impressions II and IV are V-shaped, while digit III is rather blunt. The anterior parts of the digit impressions are deeply impressed, forming triangular areas, with the deeply impressed parts of digits II and IV being interconnected via a somewhat lower, broad arc. The area between this broad arc and the deeply impressed area of digit III, as well as the very posterior part of the track, represent the shallowest parts of the track. On the deeply impressed area of digit impression IV, a longitudinal, slightly curved ridge can be observed which tapers distally. A large claw mark is present on the medial side of the distal end of digit impression III; smaller, V-shaped claw marks probably also are present on digit impressions II and IV.

\section{DFMMh/FV 645}

DFMMh/FV 645 (Figure 6; Appendix 4; Table 1) differs from all other excavated tracks due to its very large, triangular heel region and its somewhat slender and dorsoventrally constricted digit impressions which protrude from the heel without touching the ground. The footprint measures $44.0 \mathrm{~cm}$ in 


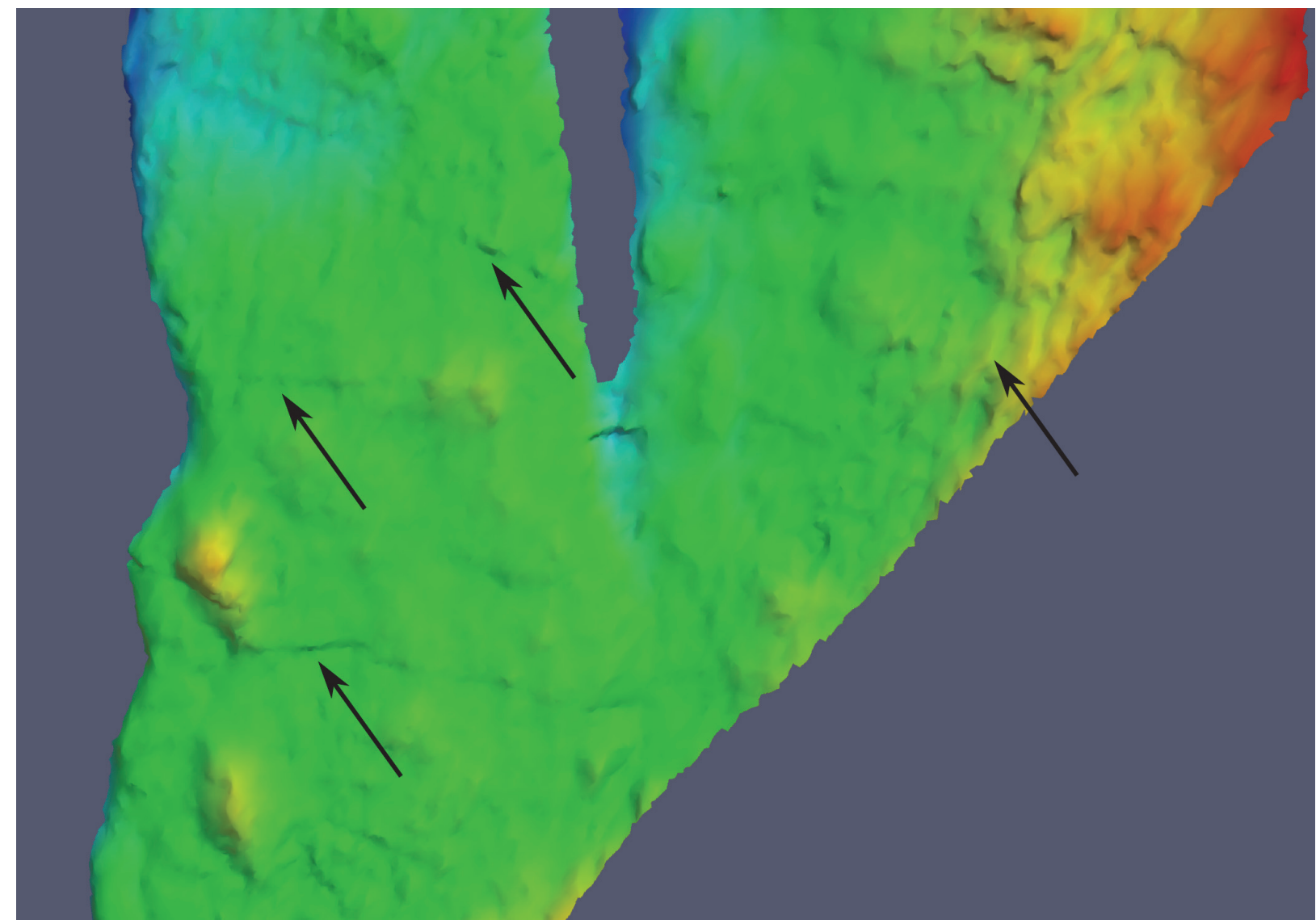

FIGURE 5. Photogrammetric pitfalls: Depth-color image of an incorrect photogrammetric model resulting from an erroneous alignment of the photographs. Arrows indicate artifacts, including crack-like structures running from the left to the right as well as longitudinal structures running down the slab which resemble ripple marks.

length, $36.7 \mathrm{~cm}$ in width, and $10.3 \mathrm{~cm}$ in depth. The footprint is deepest at the impression of digit III and in the central area posterior to the hypexes. Posteriorly, the heel region shows a gradual decrease in depth.

The morphology of this footprint (i.e., the large heel region and the slender and dorsoventrally constricted digit impressions) is commonly found in tracks emplaced deeply into a soft substrate. Since the anatomy of the trackmaker's foot is usually obscured in deep tracks (Jackson et al., 2010), detailed comparisons with the better defined footprints are not possible. Since the original position of this footprint on the slab is unknown, and since anatomical details of the footprint are obscured, it cannot be determined whether this footprint represents a left or a right one.

\section{DFMMh/FV 646}

DFMMh/FV 646 (Figure 6; Appendix 5; Table 1) measures $36.2 \mathrm{~cm}$ in length, $32.9 \mathrm{~cm}$ in width, and shows a maximal depth of $9.4 \mathrm{~cm}$. The digit impressions are featureless. The heel region is better defined, showing a pronounced asymmetry, with the pad impression on the right side of the cast located more posteriorly than the pad impression on the left side. Such asymmetry is characteristic for theropod tracks, where the more posteriorly located pad impression usually is interpreted as the metatarsophalangeal pad situated behind digit IV, and the more anteriorly located pad as the interphalangeal pad between the first two phalanges of digit II (Baird, 1957; Thulborn, 1990; Farlow et al., 2000). Thus, this footprint can be interpreted as the cast of a left footprint. The hypex between digit impression II and III is located more distally than the hypex between digit impressions III and IV. The impression of the second digit seems to be somewhat abbreviated, while the impression of digit III is markedly wide and robust along its length. Both features probably do not represent the anatomy of the trackmaker's foot. 


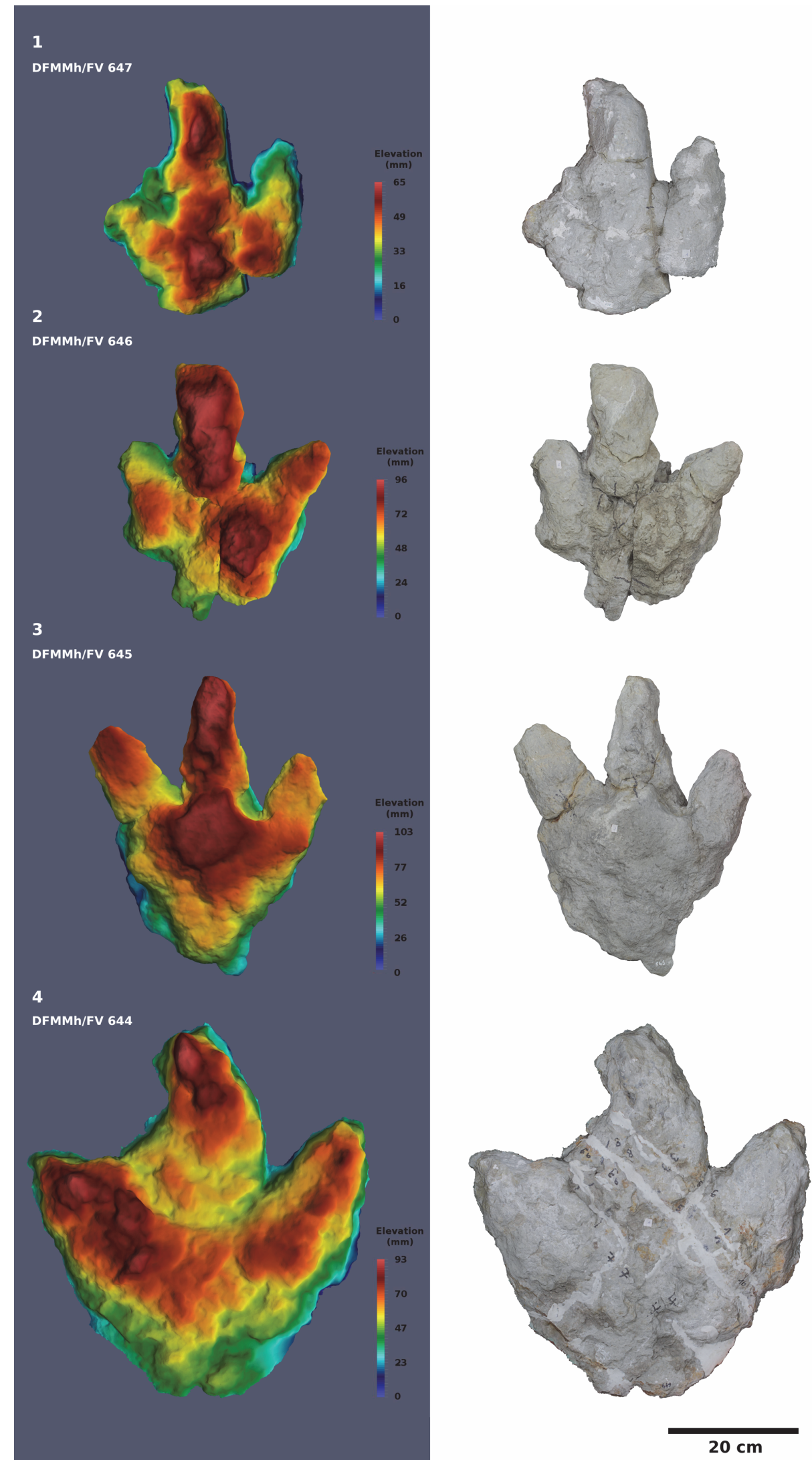

FIGURE 6. Depth-color images (left) and orthophotos (right) of 1: DFMMh/FV 647, 2: DFMMh/FV 646, 3: DFMMh/FV 645 and 4: DFMMh/FV 644. Images to scale. 
Table 1. Measurements of footprints DFMMh/FV 644-648 as indicated in Figure 3.

$\begin{array}{lcccccc}\text { DFMMh/FV Specimen no. } & & \mathbf{6 4 4} & \mathbf{6 4 5} & \mathbf{6 4 6} & \mathbf{6 4 7} & \mathbf{6 4 8} \\ & & & & & & \\ \text { Length } & {[\mathrm{cm}]} & 46 & 44 & 36.2 & 36.4 & 47.4 \\ \text { Width } & {[\mathrm{cm}]} & 52 & 36.7 & 32.9 & 34 & 48.8 \\ \text { Span } & {[\mathrm{cm}]} & 47.2 & 30.8 & 29.7 & 30 & 42 \\ \text { Depth } & {[\mathrm{cm}]} & 9.3 & 10.3 & 9.4 & 6.5 & 11.4 \\ \text { Total digit divarication } & {\left[^{\circ}\right]} & 67 & 43 & 73 & 63 & 72 \\ \text { Digit divarication II/III } & {\left[^{\circ}\right]} & 33 & 33 & 26 & 46 & 32 \\ \text { Digit divarication III/IV } & {\left[^{\circ}\right]} & 34 & 10 & 47 & 17 & 40\end{array}$

\section{DFMMh/FV 647}

DFMMh/FV 647 (Figure 6; Appendix 6 and 8; Table 1) is the least well preserved of the excavated tracks. Digit IV is separated from the remaining footprint cast through a crack running through the original slab. The footprint measures $36.4 \mathrm{~cm}$ in length and $6.5 \mathrm{~cm}$ in maximal depth. The impression of digit III is slightly curved to the left; thus, this ichnite here is interpreted as the cast of a left track, although this cannot be determined unambiguously due to poor preservation. Since parts of the footprint including the impression of digit II were lost during excavation, a separate historical photogrammetry was performed (Figure 4.1-4) based on three photographs of this footprint in situ. Based on this historical photogrammetry, the footprint width was determined as $34.0 \mathrm{~cm}$, the span as $30.0 \mathrm{~cm}$, and the total digit divarication as 63 degrees (46 degrees between digits II and III and 17 degrees between digits III and IV).

\section{DFMMh/FV 648}

DFMMh/FV 648 (Figures 7, 8; Appendix 7; Table 1) is a large left imprint measuring at least $47.4 \mathrm{~cm}$ in length. The posteriormost part of the heel was not completely freed from plaster, so the exact extend of the heel is unknown. Footprint width is $48.8 \mathrm{~cm}$. It is the deepest of the recovered footprints with a maximum depth of $11.4 \mathrm{~cm}$. All digit impressions are relatively straight, only the distal parts of digits II and III are slightly curved medially. The cast is deepest at the center of the footprint and at the proximal parts of the digit impressions.

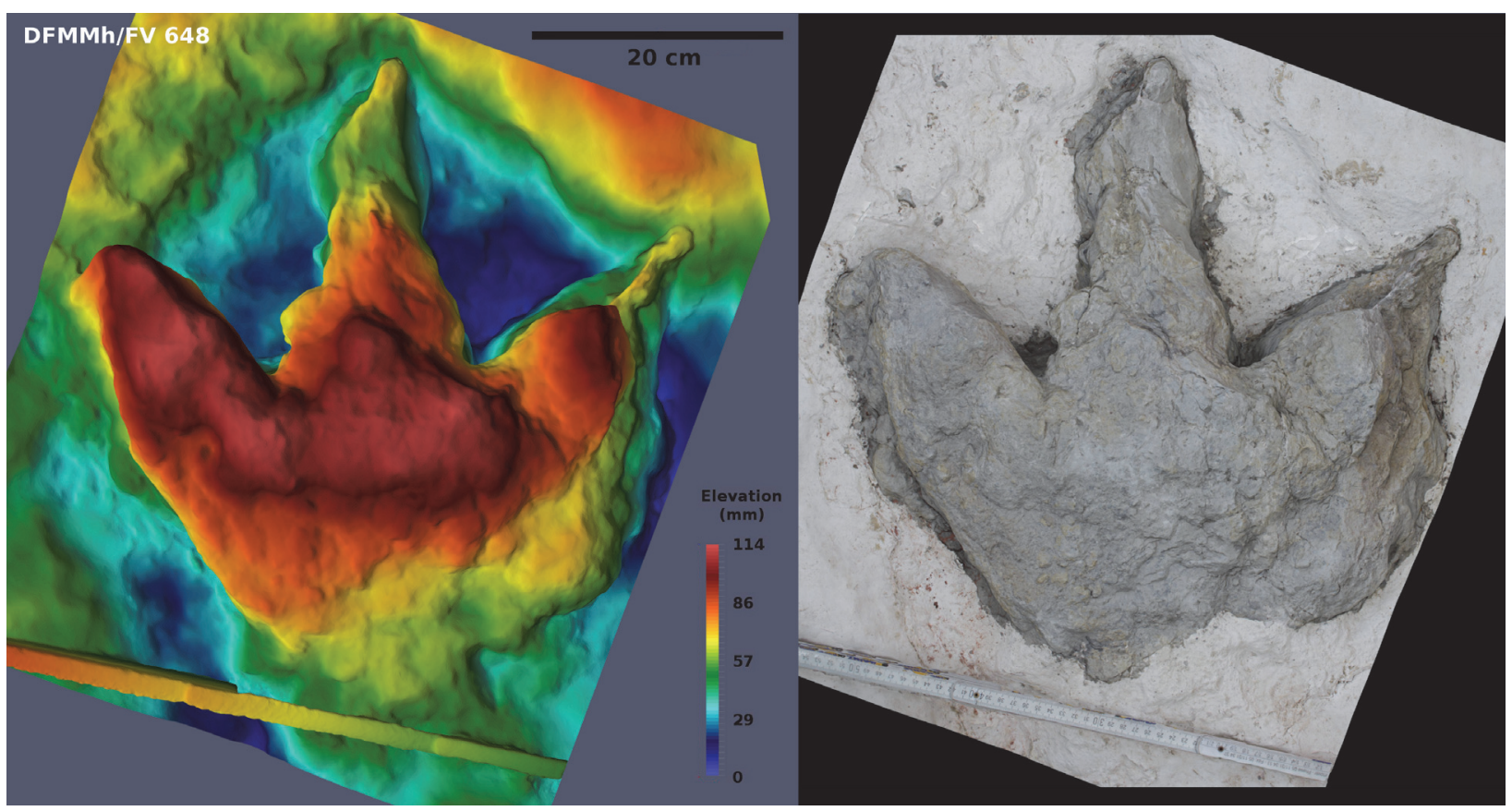

FIGURE 7. Depth-color image (left) and orthophoto (right) of DFMMh/FV 648. Not to scale with Figure 6. 


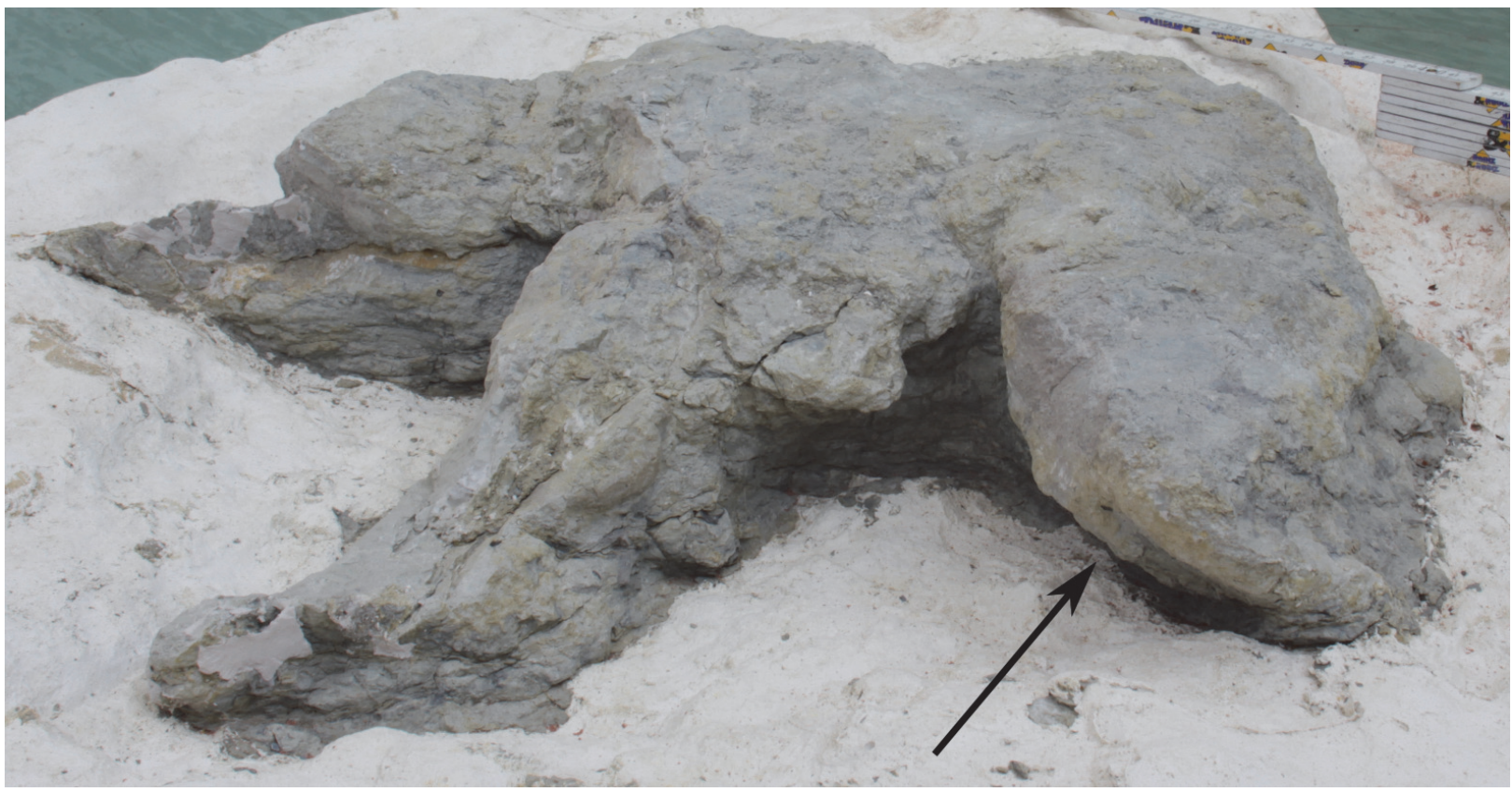

FIGURE 8. Recent photograph of DFMMh/FV 648, the best preserved footprint, photographed at a low angle. The arrow shows the strongly inclined digit impression IV.

The heel shows the pronounced asymmetry typical for theropod tracks. The bottom of digit impressions II and IV (i.e., the highest parts of their casts) are subequal in width at their bases (12.4 and $12.7 \mathrm{~cm}$, respectively), but digit impression II becomes much wider with decreasing depth, reaching $18.6 \mathrm{~cm}$ at its upper margin. Pronounced V-shaped claw impressions form the distalmost tips of all three digits. In digit III, most of the bottom of the digit impression is broken off, while on digit II the claw mark is connected via a thin longitudinal ridge to the deeper proximal part of the digit. Digit impression IV is well preserved, with only a slight decrease in depth towards its tip. The claw trace on digit impression IV runs from the base of the cast to the upper side of the digit impression, forming an arc. This digit impression is strongly tilted towards digit III along its length (Figure 8).

The strongly tilted digit impression IV records the movement of the trackmaker's foot during footprint formation (Milàn, 2006). Thus, digit IV would have entered the substrate transversely towards the medial side, and then would have been withdrawn towards the lateral side following the same way. This indicates that during the stride the foot described an outwards sweeping arc, as typical for bipedal dinosaurs (Thulborn, 1990). The longitudinal ridge seen in digit impression III can be interpreted either as a result of erosion or a result of sediment drawn inside the footprint during with- drawal of the foot. The possibility of this ridge representing an extended claw mark formed during a posterior movement of the foot within the sediment is improbable given the very well preserved digit impression IV.

\section{DESCRIPTION OF THE ORIGINAL TRACKSITE}

Measurements of the original tracksite are based on the historical photogrammetry (Figures 9, 10). Over 20 footprints representing three trackways and eight isolated footprints are recognizable in the photogrammetric model and/or photographs of the slab. Three of the isolated footprints (DFMMh/FV 644, 646 and 647) had been excavated. Two additional tracks (DFMMh/FV 645 and 648) were removed from the same slab, but their original position is no longer known. Several raised areas recognizable on the photogrammetric model may indicate additional, poorly preserved tracks, but their identity cannot be determined unambiguously.

\section{Trackway 1}

The lower part of the left slab features a $3.2 \mathrm{~m}$ long trackway composed of four consecutive footprints (tracks 6-9; Figures 11, 12.1). The pace length varies from $92 \mathrm{~cm}$ between tracks 7 and 8 to $111 \mathrm{~cm}$ between tracks 8 and 9 , with an average of $100 \mathrm{~cm}$. The stride length between footprint 6 and 8 is $185 \mathrm{~cm}$, and $200 \mathrm{~cm}$ between footprint 7 and 


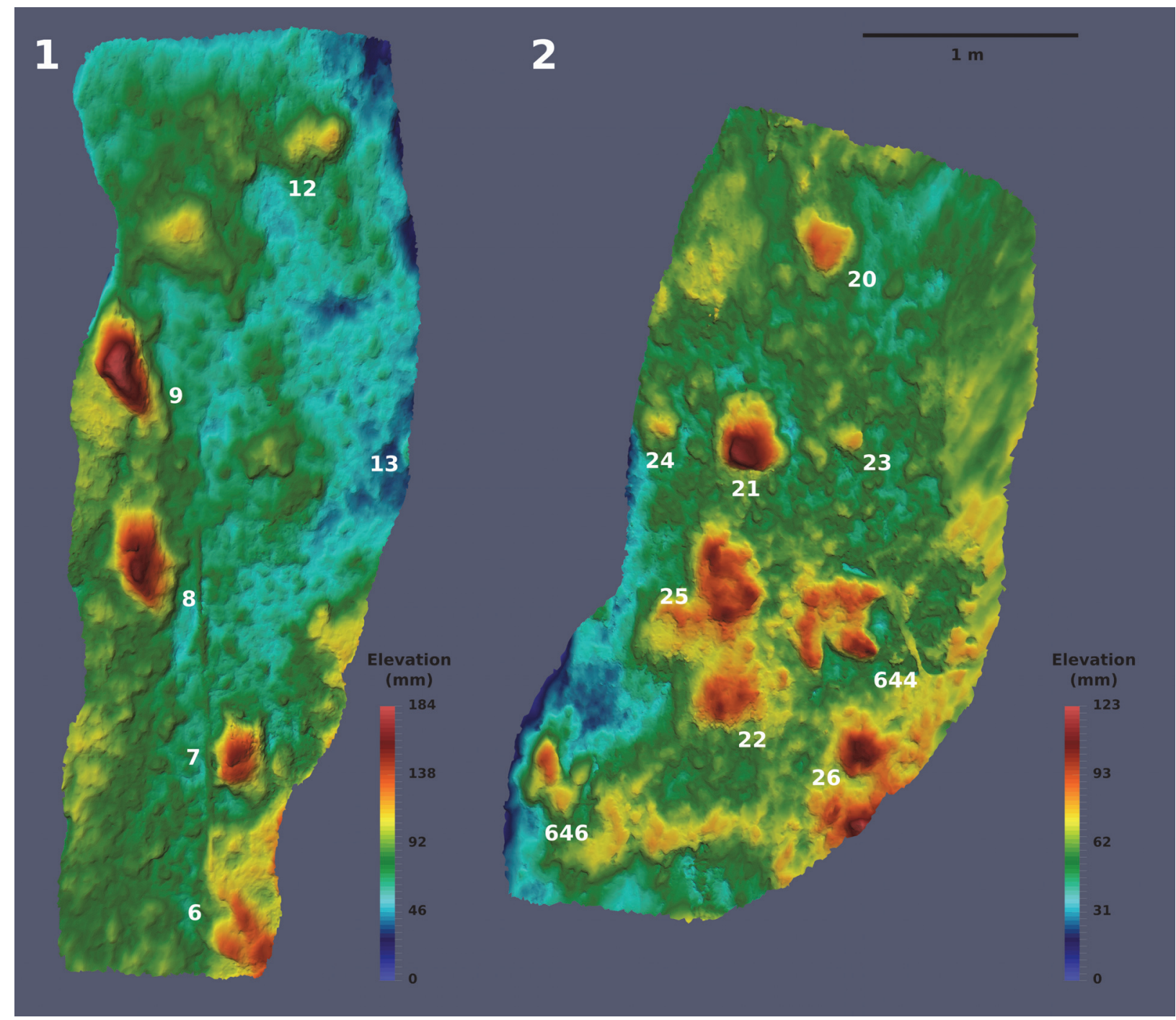

FIGURE 9. The most detailed regions of the historical photogrammetric model, shown as depth-color images. 1: Part of the left slab. Trackway 1 (footprints 6-9) and parts of trackway 2 (footprints 12 and 13) can be seen. The lineaments within trackway 1 and on the right of footprint 644 represent meter sticks incorporated into the photogrammetric model. 2: Part of the right slab. The excavated footprints DFMMh/FV 644 and 646, footprint 23, trackway 3 (footprints 20, 21, and 22) and possible additional footprints $(24,25,26)$ can be seen. Compare with Figure 10. Scale bar: $1 \mathrm{~m}, 1$ and 2 are to scale.

footprint 9 . The width of the pace angulation pattern is $17 \mathrm{~cm}$ between footprint 6 and 8 and $13 \mathrm{~cm}$ between footprint 7 and 9 , producing a more pronounced zig-zag pattern than seen in trackways 2 and 3.

Footprint 6 is the best defined, showing clear impressions of digits III and IV, while II is missing. Located at the base of the exposed part of the slab, a posterior portion of the "heel" region possibly was present but covered by sediment when the photographs were taken. The next two footprints in the sequence, footprints 7 and 8 , are deeper and more elongated, while the digit impressions become more obscure. The digit impressions, while thick at their bases, quickly become thin and irregular in shape distally. Both footprints, including digit impressions, are situated within oval elevations showing concentric lines. Footprint 7 (Figure 12.4) is triangular in shape, with digit impressions III and IV preserved and most of digit impression II being absent or broken off. A medio-distally pointing hallux impression is clearly distinguishable on both the photographs and the photogrammetry (Figures $9.1,12.4)$. The footprint, excluding the digit impressions, is $34 \mathrm{~cm}$ in length and $24 \mathrm{~cm}$ in maximum width. Immediately posterior to the hallux impres- 


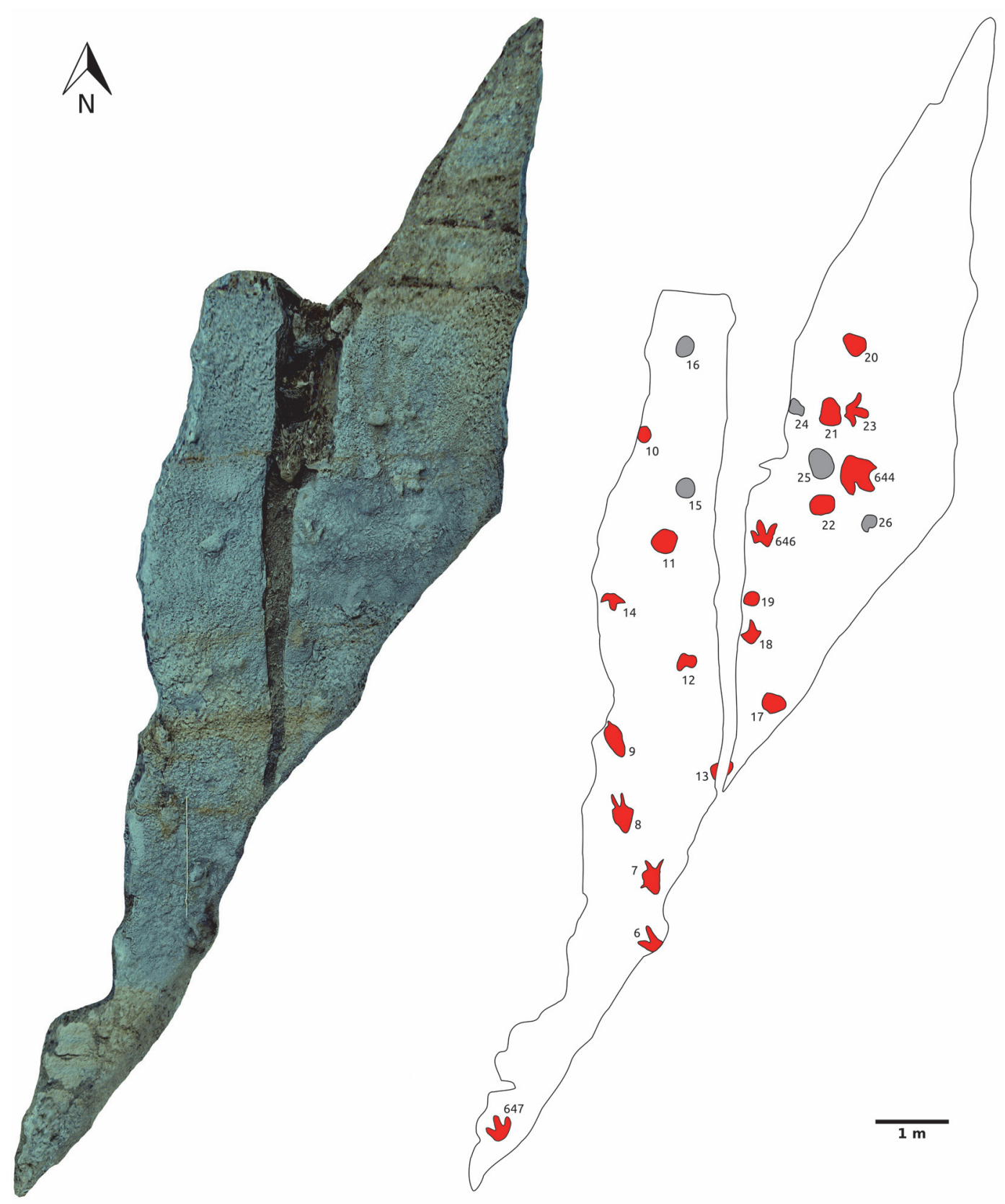

FIGURE 10. Complete historical photogrammetric model of the Langenberg tracksite. Left: Orthophoto; right: sitemap. Confirmed footprints are drawn in red, and elevations that might represent additional tracks are drawn in gray. Note that DFMMh/FV 645 and 648 do not appear on this chart, because the position of these footprints on the tracksite was not documented by photographs. Sitemap and orthophoto to scale.

sion, the heel area quickly decreases both in depth and width, forming a rounded margin at its posterior end. Footprint 8 is comparable with footprint 7 regarding depth and dimensions, measuring $35 \mathrm{~cm}$ in length and $28 \mathrm{~cm}$ in width (excluding digit impressions). As in footprint 7, digits III and IV are preserved while digit II is broken off. A hallux trace cannot be identified unambiguously. The last footprint of the sequence, footprint 9 , is the deepest of both the trackway and the whole tracksite. Measuring $46 \mathrm{~cm}$ in length excluding digit impressions, it is markedly longer than the other tracks in the trackway, while comparable in maximum width $(23 \mathrm{~cm})$. Towards its posterior end, it gradually becomes both shallower dorso-ventrally and thinner lateromedially. Only a vague impression of digit III is preserved. The other digits possibly were destroyed due to their proximity to the edge of the slab. 
Trackway 1

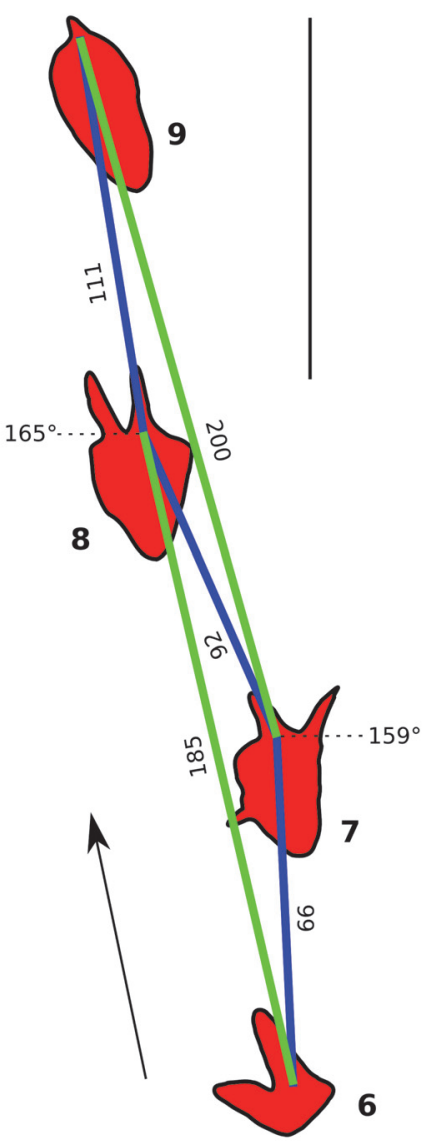

Trackway 2
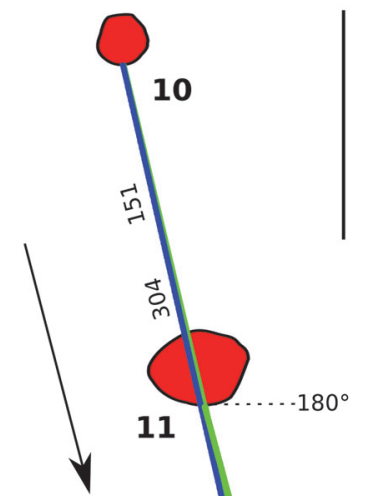

Trackway 3

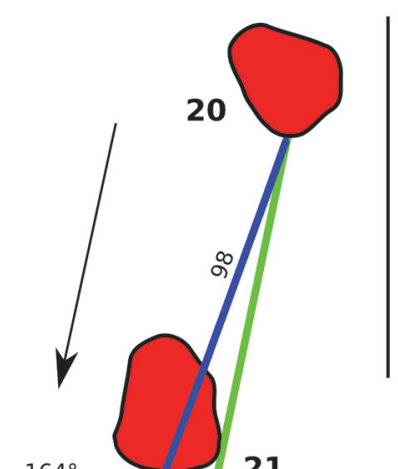

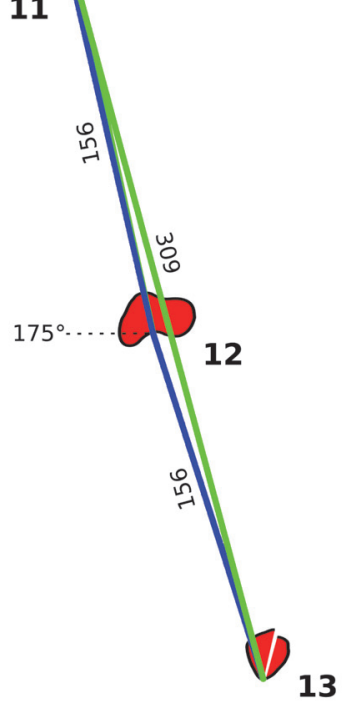

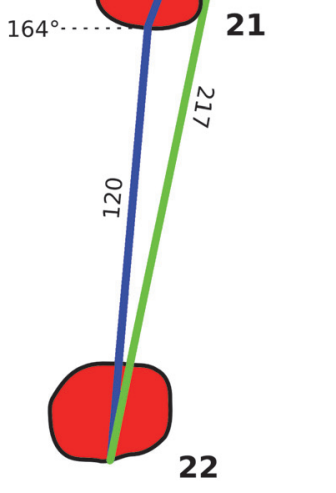

FIGURE 11. The three recognized trackways. The blue lines show the pace, the green lines the stride length. Arrows indicate direction of trackways. Measurements based on the historical photogrammetric model (pace length, stride length, and pace angulation) are included. Scale bars equal $1 \mathrm{~m}$, respectively. Trackways are not to scale.

All characteristics (i.e., the great depth of the tracks, the large and posteriorly elongated "heel" impression, the thin and irregular digit impressions, and the preserved hallux impression) are consistent with tracks imprinted very deeply into soft substrate (Gatesy et al., 1999). Footprint 6, the first footprint of the trackway, is the shallowest and shows the best defined digit impressions, while the last footprint of the trackway (footprint 9) is the deepest with the most pronounced and elongated heel impression. This suggests an increase in water content of the sediment along the trackway, leading to more deeply impressed footprints.

\section{Trackway 2}

Trackway 2 consists of four consecutive, poorly defined footprints running from the upper to the lower portion of the left slab (footprints 10-13;
Figures 11, 12.1,12.3). Detail photographs of individual footprints are not available, and especially the first two tracks are only seen at a low angle and are out of focus in most photographs, making their interpretation difficult. For this reason, the depth of the first two tracks probably is underestimated in the photogrammetry. Digit impressions are absent in all tracks.

The first three tracks are steeply sloped towards the south and gently sloped towards the north (Figure 12.3). The gently sloped part may be identified as the posterior "heel" area of a deeply impressed footprint, analogous to the posterior heel areas in trackway 1 , which gradually decrease in depth posteriorly. The steeply sloped side, on the other hand, probably marks the anterior side of the heel area from which the now broken off digit impressions had protruded. Thus, the trackway 

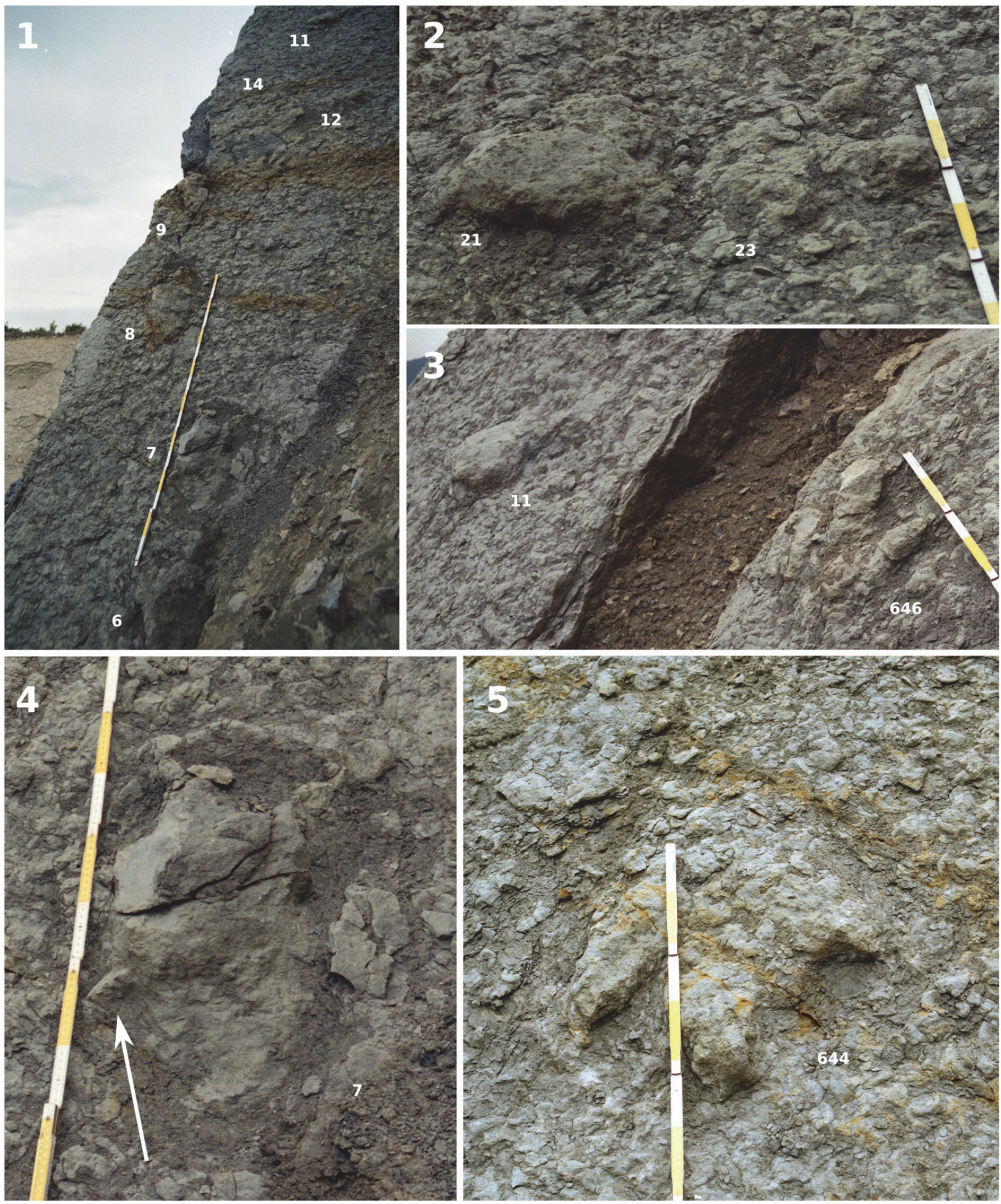

FIGURE 12. Details of the original tracksite. 1: Detail of the left slab, showing trackway 1 (footprints $6,7,8$, and 9), parts of trackway 2 (footprints 11 and 12), and the isolated footprint 14. Archival photograph by Holger Lüdtke from 2003. 2: Detail of the right slab, showing a deep track (footprint 21) and a better defined track (footprint 22) in close proximity. Digitally cropped version of an archival photograph (NK, 2003). 3: Detail of the tracksite. Footprint 11 shows the morphology typical for the deep tracks of the site. Footprint DFMMh/FV 646 is a well-defined track. Digitally cropped version of archival photograph (Nils Knötschke, 2003). 4: Footprint 7, featuring a hallux impression, as shown by the arrow. Digitally cropped version of archival photograph by NK, 2003. 5: DFMMh/FV 644, as it was in situ prior excavation. Digitally cropped version of archival photograph by NK, 2003. 
probably leads towards the south and therefore in the opposite direction of trackway 1. Alternatively, the steeply sloped sides may be interpreted as a product of erosion, since they are facing down the slab. Further complicating the interpretation of this trackway, the tracks are not uniform in shape. Footprint 10 is markedly smaller than footprint 11 , the largest footprint of the sequence, while footprint 12 is irregular in shape. Footprint 13 appears to be rounded, though this footprint is broken into two halves due to the crack separating the left from the right slab. The shape differences probably are a result of preservation (e.g., differences in substrate consistency at the time of footprint formation) or of recent erosion, or both.

Despite these difficulties, the sequence here is interpreted as a single trackway, based on the following observations. First, the distance or pace length between all the four tracks is nearly identical, ranging only from $151 \mathrm{~cm}$ between footprint 10 and 11 to $156 \mathrm{~cm}$ between footprint 12 and 13 . The stride length also is very similar, measuring $304 \mathrm{~cm}$ between footprint 10 and 12 and $309 \mathrm{~cm}$ between footprint 11 and 13. Finally, the tracks nearly form a single line. The width of the pes angulation pattern is barely perceptible at the stride between footprint 10 and 12, measured at less than $2 \mathrm{~cm}$, and somewhat larger at the stride between footprint 11 and 13, measured at $6 \mathrm{~cm}$. The large pace and stride length, in combination with the very narrow trackway, is consistent with a faster locomotion of the trackmaker.

\section{Trackway 3}

Trackway 3 consists of three consecutive tracks (footprints 20-22; Figure 11), running down the upper part of the right slab. Footprint 21 is the best preserved, consisting of a rounded impression approximately $30 \mathrm{~cm}$ in width that is steep at its southern end (facing down the slab) and slopes gently at its northern end. Footprint 20, while also being steeply sloped at the southern end, is triangular in shape and, judging from the photographs, shallower than footprint 21 . Footprint 22 probably can also be identified as a footprint of this trackway, though being eroded with only the base remaining. The pace length is $98 \mathrm{~cm}$ between footprint 20 and 21 and $120 \mathrm{~cm}$ between footprint 21 and 22, while the stride length measures $217 \mathrm{~cm}$. The width of the pace angulation pattern is $14 \mathrm{~cm}$.

\section{Isolated Footprints}

Several other footprints, including all welldefined ones, cannot be ascribed to any trackway.
On the left slab, two well-defined footprints had been found. DFMMh/FV 647, which was excavated, was situated in the lowermost portion of the slab and directed towards the north. Footprint 14, directed towards the south, is located in the middle part of the slab. Additional tracks (15 and 16) were recorded by the excavators as possible further footprints, but cannot be verified unequivocally based on the photographs. On the right slab, isolated footprints include DFMMh/FV 646 and DFMMh/FV 644, both of which were excavated. $\mathrm{DFMMh} / \mathrm{FV} 646$ is directed towards the north, while the very large DFMMh/FV 644 is directed towards the south-east. Footprint 23, measuring 31 $\mathrm{cm}$ in length, is similar to DFMMh/FV 646, although showing a higher total divarication angle (approximately 130 degrees). Measurements for footprint 23 are exclusively taken from the historical photogrammetry. Footprint 18, directed towards the north, probably forms the preceding footprint of DFMMh/FV 646, suggesting that the two footprints are part of the same trackway. No detail photographs are available, and most of the natural cast had eroded away at the time of discovery, exposing a yellowish silhouette. Footprint 17 and 19 are rounded impressions lacking digit impressions. Although the resolution of footprint 17 in the photogrammetric model is unsatisfactory, the only detailed photograph available for this footprint indicates a roughly triangular outline, with the base of the triangle (where digit impressions would have been located) orientated approximately towards the west. The direction of footprint 19 cannot be determined. Further structures that might also represent footprints are located west and south of DFMMh/FV 644, but cannot be identified unequivocally.

\section{DISCUSSION}

\section{Genesis and Preservation of the Tracksite}

The very different morphology of the tracks ranging from deeply impressed, rounded or triangular to well defined but shallower tridactyl footprints - probably is the result of changing substrate conditions, possibly both in time and space. In carbonates, deep tracks usually form in water-saturated, unconsolidated substrates (cf. Marty et al., 2009). Well defined tracks showing a high degree of anatomical detail form in moist substrates which are neither water-saturated nor dry (Marty et al., 2009). On one hand, trackway 1 , which consists of deep tracks, becomes deeper towards its northern end, possibly recording an increasing water con- 
tent of the sediment at the time of track formation. On the other hand, the close proximity of both welldefined and deeply impressed footprints, which is best seen in footprints 21 and 23 (Figure 12.2), indicates that the main change in substrate properties occurred over time. The deeply impressed tracks probably were left while the substrate had a high water content, while the better defined tracks were left during another period, when the substrate was more competent.

Undertracks, i.e., tracks transmitted through a succession of sediment layers, can be very different in morphology than their respective true tracks (e.g., Milan and Bromley, 2007; Milàn, 2006); their recognition therefore is of great importance for the interpretation of footprints. Undertrack formation, however, is restricted to layered sediment that differs only slightly in composition (Thulborn, 1990), and undertracks are not as common as previously thought (Marty et al., 2009). The Langenberg footprints are not regarded as undertracks but true tracks (i.e., tracks left on the tracking surface) or, alternatively, underprints (i.e., deep tracks left below the tracking surface due to penetration of the foot through the sediment (e.g., Thulborn, 1990; Falkingham and Gatesy, 2014)), based on the following evidence. First, the sedimentary conditions are not favorable for undertrack formation. If the tracks would represent undertracks, additional undertracks and/or true tracks could be expected in the overlaying sediment of bed 94, which was not the case. Second, a hallux impression is preserved with footprint 7 . Hallux impressions are usually only preserved in footprints emplaced deeply into the substrate (Gatesy et al., 1999), because the hallux usually does not contact the ground. Not being a weight-bearing digit, it is improbable that this impression will register as an undertrack together with the much deeper impressed remaining part of the footprint. Third, digit impression IV in DFMMh/FV 648 is strongly inclined. In an undertrack, this feature would be expected to be significantly less pronounced.

At the time of discovery, some footprint casts already had fallen down from the slab, possibly indicating an additional thin sediment layer between the casts and layer 94, acting as detachment layer. Thus, the footprints possibly had been partly filled with sediment before layer 94 was deposited, and therefore potentially do not belong to that layer. It was not possible to identify this possible detachment layer on the archival photographs. Alternatively, the partial separation of the footprint casts from layer 94 might be explained by tectonically induced fractures.

\section{Identity of the Trackmakers}

All well-defined footprints are functionally tridactyl. Initially, several poorly defined footprints lacking digit impressions from the Langenberg tracksite were thought to belong to small sauropods (Nils Knötschke [2004], cited in Marty, 2008). These footprints, however, appear to be deep tracks also left by a functionally tridactyl trackmaker, with the digit impressions either broken off or not preserved.

Mesozoic tridactyl tracks are either referred to theropod or ornithopod dinosaurs. The distinction between non-avian theropod and ornithopod tracks continues to cause much controversy (e.g., Romilio and Salisbury, 2010, 2014; Thulborn, 2013). In general, ornithopod tracks often are wider than long with short, broad and blunt digits, while theropod tracks are longer than wide and show slender, tapering digits with claw marks (Thulborn, 1990). Digit divarication between digits II and IV is higher in ornithopod tracks, and the posterior end ("heel") is rounded and symmetrical in ornithopod tracks and asymmetric in theropods (Lockley, 1991). Two recent approaches also use bi- and multivariate analyses to discriminate between ornithopod and theropod footprints (Moratalla et al., 1988; Castanera et al., 2013). The three best preserved footprints (DFMMh/FV 644, 646 and 648) can confidently be referred to a theropod trackmaker, based on the $\mathrm{V}$-shaped claw impressions seen in DFMMh/FV 644 and 648, the medially curved digit III seen in DFMMh/FV 644, the long and slender digit impressions seen in DFMMh/FV 648, and the asymmetrical heel seen in DFMMh/FV 646 and DFMMh/FV 648. The great width of the two largest footprints (DFMMh/FV 644 and 648) suggests that a high width-length ratio is not an infallible criterion for the discrimination between ornithopod and theropod tracks. For the less well preserved footprints (DFMMh/FV 647 and DFMMh/FV 645), an ornithopod origin cannot be excluded, since DFMMh/FV 647 is poorly preserved and DFMMh/ FV 645 is a deep track, poorly reflecting the anatomy of the foot of the trackmaker (Jackson et al., 2010).

Pedal morphology within theropods is rather conservative (Lockley et al., 1998a). Few groups, such as deinonychosaurs, ornithomimosaurs, therizinosaurs (e.g., Fiorillo and Adams, 2012), and birds show distinctive pedal morphologies that are easily recognizable in their footprints (Thulborn, 
1990). At present, it is not possible to differentiate the tracks of the major groups of large theropods, because their pedal morphology was very similar, possibly because gigantism constrained variability in foot shape (Farlow et al., 2013).

One approach to differentiate tracks of separate taxa of large theropods possibly lays in the analysis of the trackway pattern (Lockley, 2000; Lockley and Meyer, 2000). Based on the high variability in both trackway width and step length, Lockley (2000) and Lockley and Meyer (2000) argued that large Late Jurassic theropod tracks referable to the ichnogenus Megalosauripus might have been produced by megalosauid trackmakers. These authors cited Bakker (1996), who suggested that megalosaurs and ceratosaurs showed proportionally longer bodies and shorter legs than more advanced theropods. According to Lockley (2000) and Lockley and Meyer (2000), this bauplan is consistent with the observed irregular trackway configuration in Megalosauripus. Any possible relationship between the megalosaur bauplan and the trackway configuration, however, has still to be verified by further evidence. Only a quantitative statistical analysis can show if these variations in the trackway pattern can serve to differentiate different groups of theropods, or perhaps are only a function of trackmaker speed. In the trackways from the Langenberg, trackway width is extremely narrow in trackway 2 and widest in trackway 1 . In the latter, the wider gauge could be a result of changed substrate properties, which caused the trackmaker to sink in deeply and thus reduce its speed. The speeds of the trackmakers producing the Langenberg trackways were not calculated because the footprint length could not be measured precisely due to the elongated heel impressions and poor preservation of the digit impressions.

\section{Minimum Number of Trackmaker Species}

Occasionally it is possible to estimate the minimum number of trackmaker species of an ichnoassemblage, as pedal morphology can vary between low-level trackmaker taxa (Farlow et al., 2013). Features traditionally used for distinguishing footprint types include shape and length of the digit impressions, elongation of the footprint, digit divarication, position of the hypexes, and number and morphology of digital pads, among others (Lockley et al., 1998a). Recent neoichnological studies, however, show that both the substrate properties and the kinematics of the trackmaker's foot can have a greater influence on footprint morphology than previously thought (cf. Falkingham, 2014). The degree of variation caused by the latter two faactors cannot be constrained sufficiently to date and necessitates further neoichnological studies. The digit shape in the Langenberg footprints can be both wide and robust as in DFMMh/FV 644 or slender and irregular as in footprints 7 and 8 of trackway 1 , probably strongly depending on the water content of the sediment at the time of track formation. Horizontal movements of the foot within the sediment during track formation may also alter the morphology of the digit impressions and the position of the hypexes. The digit divarication shows some variation in the Langenberg footprints, varying from $43^{\circ}$ to $73^{\circ}$ in the excavated tracks. However, digit divarication can vary with different substrate conditions (Lockley, 2010; Wings et al., 2007). The divarication angle of modern emu tracks is very inconsistent, ranging from $61^{\circ}$ to $102^{\circ}$ in only 30 footprints of a single individual (Milàn, 2006). Digit divarication can also vary with the depth within the same footprint (Milàn, 2006). This also is observable in DFMMh/FV 648, where the strongly inclined digit impression IV leads to a progressively smaller digit divarication towards the bottom of the footprint. Anatomical details like digital pad impressions are rarely recognizable and occur only in the best preserved footprints from the Langenberg Quarry. Consequently, and in combination with the very limited sample size, these features are not available for distinguishing separate trackmaker taxa.

Of the excavated footprints, DFMMh/FV 644 and 648 (mean pes length $46.7 \mathrm{~cm}$ ) are significantly larger than DFMMh/FV 646 and DFMMh/FV 647 (mean pes length $36.3 \mathrm{~cm}$ ). DFMMh/FV 645 is not directly comparable in terms of pes length, because the elongated metatarsus impression leads to a more elongated footprint shape. This difference in size can be explained either by different trackmaker species or ontogenetic stages of the same trackmaker species. DFMMh/FV 644 and 648 further differ from DFMMh/FV 646 and DFMMh/FV 647 in being subequal in length and width, with a mean width-length ratio of 1.08 . In DFMMh/FV 646 and DFMMh/FV 647, the mean width-length ratio is lower, averaging at 0.92 . The observed pattern possibly follows a general trend noted by Lockley (2010) that is observable in tridactyl footprints of theropods, ornithopods, and birds: Large tridactyl footprints in general tend to be proportionally wider than smaller ones. Applying the external phylogenetic bracket on theropod dinosaurs, both recent alligator and emu footprints 
are nearly isometric across their ontogenetic size range (Farlow et al., 2012). Emus, however, show a negative allometry in footprint width (Farlow et al., 2012). Based on very limited evidence (the greater size and greater width-length ratio of DFMMh/FV 644 and 648), we suggest that at least two trackmaker species were present at the Langenberg.

\section{Implications for the Insular Dwarfism Hypothesis}

Abundant remains of the dwarf sauropod Europasaurus have been discovered in bed 83 of the Fischer (1991) stratigraphy, which, according to the measured section provided by Fischer (1991), is separated from the track layer by approximately $5 \mathrm{~m}$ (Figure 3). The Europasaurus bones are very well preserved, indicating a relatively short distance of post mortem transport. Theropod teeth from bed 83 might be attributable to members of the Megalosauridae, Allosauroidea, Tyrannosauroidea, and Dromaeosauridae (Oliver Gerke, personal commun., 2014; Gerke and Wings, 2014). The largest theropod tooth, probably belonging to the Megalosauridae, measures $24 \mathrm{~mm}$ in crown high; the length of this theropod can be roughly estimated at around $4 \mathrm{~m}$ (Oliver Gerke, personal commun., 2014). The adult body length of Europasaurus was estimated at $6.2 \mathrm{~m}$ by Sander et al. (2006) but might have reached $8 \mathrm{~m}$ as indicated by new fossil material. These observations are in accordance with the hypothesis that the terrestrial fauna of bed 83 represents a dwarfed island fauna. The track layer, being the oldest known emergent surface in the Langenberg succession, probably indicates a sea level fall which might have allowed the immigration of theropods much larger than anything known from the dwarfed island fauna of bed 83.

Any estimation of hip height and dinosaur speeds from tracks must generally be considered with caution (Rainforth and Manzella, 2007). Nevertheless, out of various formulas used to predict hip height based on bipedal dinosaur tracks, the simple relationship of hip height being equal to 4 times footprint length (Alexander, 1976) has been shown to be the most accurate (Henderson, 2003). According to this formula, the hip height (i.e., the average height of the acetabula above the ground during locomotion) for the two largest footprints, DFMMh/FV 644 and 648, is $184 \mathrm{~cm}$ and $190 \mathrm{~cm}$, respectively. Assuming body proportions similar to those of Allosaurus (Hartman, 2013), the calculated hip heights would translate into a body length of roughly 7 to $8 \mathrm{~m}$ for the largest Langenberg trackmakers.

It is plausible that such a faunal interchange would have eliminated a specialized dwarfed island fauna. Thus, the dinosaur track layer 93 probably marks the maximum upper limit of the temporal distribution of Europasaurus.

\section{Comparison with Theropod Ichnogenera}

Lockley et al. (1998a) introduced the ichnogenus Megalosauripus to describe certain Jurassic tracks from North America, Asia, and Europe. The type species is Megalosauripus uzbekistanicus, based on tracks from Uzbekistan previously known as "Megalosauropus" uzbekistanicus. Many of the features listed by Lockley et al. (1998a) to diagnose the ichnogenus are common to most theropod tracks. The only features noted by Lockley et al. (1998a) that may distinguish this ichnogenus from related ichnogenera are the elongated shape, the elongated heel region, and the variable trackway pattern. Lockley et al. (1998a) attributed the Barkhausen theropod tracks to a ichnospecies of Megalosauripus, Megalosauripus teutonicus, although these tracks show none of the features that distinguish Megalosauripus from other large theropod ichnogenera: These footprints are only slightly longer than wide and thus not elongated, while the trackway pattern is narrow and regular (Lockley et al., 1998a). The mean width-length ratio of footprints DFMMh/FV 644 and 648 from the Langenberg is even larger than that of the Barkhausen tracks (1.08 vs. 0.88). The trackways known from the Langenberg are very narrow (trackway 2) or moderately wide (trackway 1 and 3 ), but in all cases rather regular. In conclusion, the Langenberg tracks are more similar to the tridactyl tracks from Barkhausen than to Megalosauripus as defined by Lockley et al. (1998a). However, DFMMh/FV 645 from the Langenberg also closely resembles tracks from Portugal and Spain identified by Lockley et al. (1998a) in showing an elongated, distally tapering heel impression and irregular digit impressions. DFMMh/FV 645 here is interpreted as a deep track that does not reflect the anatomy of the trackmaker, and the same may be true for several other elongated footprints ascribed to Megalosauripus.

Lockley et al. (1998b) described the new ichnogenus and species Therangospodus pandemicus, based on tracks from the lower part of the Upper Jurassic from two sites in Utah (USA) and one site in Turkmenistan. A second species from Spain, Therangospodus oncalensis, also was 
assigned to this ichnogenus (Lockley et al., 1998b), but has recently been shown to pertain to an ornithopod (Castanera et al., 2013). In the North American and Central Asian sites, Therangospodus is associated with larger tracks assigned to Megalosauripus, forming a "MegalosauripusTherangospodus" track assemblage (Lockley et al., 1998b). Marty (2008) described Therangospodus tracks from the Kimmeridgian of the Swiss Chevenez Combe Ronde tracksite. While the Megalosauripus tracks from these sites are consistently larger and show discrete digital pad impressions as well as wide and irregular trackways, the smaller Therangospodus lacks discrete digital pad impressions and shows narrow trackways with a long step. The lack of discrete pad impressions may indicate a trackmaker with well-padded feet (Lockley et al., 1998b). Milàn (2006), however, indicated that such a lack of anatomical details is an indicator for undertrack preservation. All tracks from the Langenberg Quarry with the exception of DFMMh/ FV 646 and 648 lack clear digital pad impressions. The lack of such impressions in the Langenberg tracks is interpreted as a result of substrate properties unfavorable to the preservation of anatomical details.

The individual footprints of trackway 1 , especially footprint 7 , resemble isolated footprints from the Lower Cretaceous Obernkirchen Sandstone described by Kuhn (1958) as Bueckeburgichnus maximus (e.g., Lockley, 2000, color plate VI). Lockley (2000) diagnosed this ichnogenus as a large theropod track with a small hallux impression. The hallux and the elongated and tapering heel impression, however, show that both trackway 1 and the isolated Bueckeburgichnus footprints represent deep tracks. We consider the definition of ichnotaxa based on such deep tracks problematic, because the footprint morphology of such tracks usually does not reflect the anatomy of the trackmaker accurately (Jackson et al., 2010). Other diagnostic features of Bueckeburgichnus are the wide and well-padded digit II and the narrow digit IV, with the latter showing discrete digital pads (Lockley, 2000). This morphology resembles that of DFMMh/FV 648 from the Langenberg, which also shows a wide digit II and a narrower but more complete digit IV. This combination of features is considered a result of the deep nature of the footprints, and is not diagnostic for specific ichnogenera. The validity of Bueckeburgichnus as a distinct ichnotaxon thus appears questionable.

A similar track type with a distinctive hallux trace was reported by Nopsca (1923) from the Late
Jurassic of Portugal and named Eutynichnium. This ichnogenus was considered distinctive in a recent description because of the anteromedially facing hallux impression (Lockley et al., 1998a). It remains to be proven, however, that this different orientation of the hallux reflects an anatomical feature. Eutynichnium as illustrated by Lockley et al. (1998a, figure 7) resembles DFMMh/FV 645 and the footprints of trackway 1 from the Langenberg, showing irregular and featureless, sometimes abbreviated or distally narrowing digit impressions, and elongated, distally tapering heel impressions. These features are consistent with preservation as deep tracks (Lockley and Meyer, 2000). Yet another theropod track showing a hallux trace was described based on a single footprint cast from the Upper Cretaceous of New Mexico (USA) and named Tyrannosauripus (Lockley and Hunt, 1994). As in Bueckeburgichnus and DFMMh/FV 648 from the Langenberg, digit impression II is markedly wider than that of digit IV. Lockley (2000) argued that the similarity to Bueckeburgichnus could hint at a close phylogenetic relationship of the trackmakers. However, as shown by DFMMh/FV 648, this feature has a broader distribution among theropod tracks, and probably is related to the preservation as deep tracks. Other features of Tyrannosauripus listed as diagnostic by Lockley (2000) fail to differentiate the ichnogenus from other large theropod ichnogenera like Megalosauripus. Despite the larger size (footprint length including heel is $86 \mathrm{~cm}$ ) and the slightly more elongated morphology, Tyrannosauripus cannot be differentiated from DFMMh/FV 648.

\section{Comparison with Other Tracks from the Late Jurassic of Central Europe, with Detailed Comments on Diedrich (2011b)}

The Late Jurassic track record of Central Europe is dominated by sauropod tracks, with only occasional occurrences of tracks referable to large theropods. All Central European sites except for the Barkhausen tracksite are preserved in carbonates. As most occurrences have not been described yet, only tracks for which published measurements are available are reviewed herein.

The most extensive dinosaur track record comes from the Kimmeridgian Reuchenette Formation of Switzerland (Marty, 2008). Poorly preserved theropod footprints possibly representing undertracks have been reported from the Courtedoux-Sur Combe Ronde site in the Canton Jura (Marty et al., 2003). These tracks pertain to two trackways and measure between 24 and $29 \mathrm{~cm}$ in 
length and 27 and $34 \mathrm{~cm}$ in width; thus they are slightly wider than long (Marty et al., 2003). Another tracksite from the same area, the Courtedoux-Bois de Sylleux site, is remarkable as it features very large theropod tracks with a footprint length of $\mathrm{ca} .80 \mathrm{~cm}$ together with the tracks of very tiny sauropods (Marty and Billon-Bruyat, 2009). Tracks of medium-sized theropods also have been reported (Marty and Billon-Bruyat, 2009). A single, $40 \mathrm{~cm}$ long theropod footprint was described from the La Heutte II site in Canton Bern by Meyer and Hauser (1994). This footprint is longer than wide (FW/FL ratio is 0.82) and shows claw impressions (Meyer and Hauser, 1994).

Both medium-sized theropod tracks (20-30 $\mathrm{cm}$ in length) and very large theropod tracks (up to $80 \mathrm{~cm}$ in length) have recently been reported from the late Oxfordian Loulle site in the Département du Jura in France (Cariou et al., 2014; Marty et al., 2013). A single large theropod footprint from the late Oxfordian Błaziny site in the Holy Cross Mountains in Poland was described in detail by Gierliński and Niedźwiedzki (2002). This footprint is $43 \mathrm{~cm}$ long and $30 \mathrm{~cm}$ wide; discrete phalangeal pads are absent, which was considered to be caused by preservational conditions (Gierliński and Niedźwiedzki, 2002).

Until 2002, the Kimmeridgian Barkhausen tracksite in the Wiehen Mountains in Bad Essen, Lower Saxony, was the only known tracksite from the Late Jurassic of Germany. Described in 1974 by Kaever and Lapparent, it includes tracks of large tridactyl dinosaurs (ascribed to theropods) and the first sauropod footprints discovered in Europe (Le Lœuff et al., 2006). The two tridactyl trackways are of approximately the same size (Lockley and Meyer, 2000; Kaever and Lapparent, 1974; Diedrich, 2011b). The footprints measure 63 $\mathrm{cm}$ in length (Lockley and Meyer, 2000) and thus are larger than the footprints from the Langenberg quarry. Although having been ascribed to large theropod trackmakers by previous authors (Lockley and Meyer, 2000; Kaever and Lapparent, 1974; Diedrich, 2011b), these footprints are very variable in shape, indicating that the footprint morphology does not fully reflect the anatomy of the foot of the trackmaker (personal observation, JNL). As some of these footprints range well within the morphospace typical for ornithopod footprints, an ornithopod origin of these tracks cannot be excluded at present.

In 2011, C. Diedrich published his work "Upper Jurassic tidal flat megatracksites of Germany - coastal dinosaur migration highways between European islands, and a review of the dinosaur footprints." This work was aimed to provide a much needed reinterpretation of Barkhausen, to introduce two additional sites, and to propose a number of novel hypotheses. Here we argue that several of the conclusions made in Diedrich (2011a) are not tenable due to serious errors and insufficient evidence. Other works by Diedrich have been criticized previously (Scheyer et al., 2012; Tintori, 2011). Scheyer et al. (2012) claimed a "[...] narrow scope of presenting and discussing data, including omitted articles relevant to the topic, and over-interpretation of results [...]" for a recent article presenting the hypothesis of placodonts being Triassic analogues to sea cows feeding on macroalgae (Diedrich, 2011a). Our following discussion is written in a similar fashion. We consider this extended discussion necessary because many of its conclusions are relevant for the understanding of Late Jurassic dinosaur track record in Central Europe, including the Langenberg tracksite.

Megalosauropus Kaever and Lapparent 1974 is not a valid ichnotaxon. First being described as Megalosauropus teutonicus nov. gen., nov. sp. by Kaever and Lapparent (1974), this ichnospecies later was ascribed to the newly erected ichnogenus Megalosauripus by Lockley et al. (1998a). Diedrich (2011b) stated that the name Megalosauropus Kaever and Lapparent 1974 has priority over Megalosauripus Lockley 1998 and that the referral of the tracks to the latter ichnotaxon violates the International Code of Zoological Nomenclature. Thus, he declared Megalosauropus as the valid name for theropod tracks from Barkhausen and other sites "in the Kimmeridgian of northern Switzerland, southern England and western Portugal" (p. 142). Based on this evaluation, Diedrich (2011b) criticized that "the holotype Megalosauropodus [sic] was not used" (p. 147) for theropod tracks from the Swiss Chevenez-Combe Ronde site described by Marty (2008).

As noted by other authors (Lockley et al., 1998a, 1996; Thulborn, 2001), the name Megalosauropus Kaever and Lapparent 1974 is invalid since it was preoccupied, having already been erected by Colbert and Merrilees (1967) for theropod tracks from the Lower Cretaceous Broom Sandstone of Western Australia. Thus, the referral of any track to Megalosauropus Kaever and Lapparent 1974 is clearly in error.

Regarding the description of the Barkhausen theropod tracks in Diedrich (2011b), we wish to point out several additional errors. While the diag- 
nosis section reads "Tridactyl bipedal of a large size with claw impressions" (p. 142), later in the text it was contradictorily noted that "Neither this trackway nor Trackway B reveal digital pads or clear claw marks" (p. 143). In Figure 11b (p. 142), the pedal skeleton of Allosaurus is projected into an outline drawing of the "track Megalosauripus [sic] teutonicus Kaever and Lapparent, 1974," demonstrating the fit of the described tracks with the proposed foot of the trackmaker. However, digit IV of the pedal skeleton is wrongly projected into digit impression II of the outline drawing, while digit II is wrongly projected into digit impression IV. Consistently throughout the paper, the term "negative" is obviously used to refer to tracks preserved as convex hyporeliefs, while the term "positive" is used for concave epireliefs. While these terms are not completely unambiguous, in ichnology they usually convey converse meanings, with the term "negative" referring to the mould (the negative of the animal's foot), and the term "positive" to the cast (the positive copy of the mold) (Leonardi, 1987).

Elephantopoides Kaever and Lapparent 1974 does not qualify as the valid name for many Jurassic and Cretaceous sauropod tracks. Diedrich (2011b) indicated that the ichnogenus Elephantopoides, established by Kaever and Lapparent (1974) for the Barkhausen sauropod tracks, has priority over the established ichnogenera Brontopodus, Parabrontopodus, and Breviparopus in case of synonymy. He noted that the "ichnogenera Rotundichnus from the Lower Cretaceous Berriassian [sic] of Münchehagen in northwestern Germany [...] or the Jurassic-Cretaceous Brontopodus, Parabrontopodus, and Brevirparopus [sic] created [...] from North American or Portuguese sauropod trackways, seem to be, at least in some cases, nothing more than tracks of the Elephanotopoides [sic] ichnogenus track-type" ( $p$. 139). Contrary to this statement, none of the mentioned ichnogenera was created based on Portuguese sauropod trackways.

The most widely used sauropod ichnogenera - Brontopodus Farlow et al. 1989 and Parabrontopodus Lockley et al. 1994 - are diagnosed based on both trackway parameters (i.e., gauge and heteropody) and anatomical details (i.e., claw impressions, and, in the case of Brontopodus, digit impressions). Since the Barkhausen sauropod tracks do not show anatomical details, Elephantopoides was considered a nomen dubium in recent reviews (Wright, 2005; Lockley et al., 1994) and therefore currently cannot qualify as a senior sub- jective synonym of Brontopodus or Parabrontopodus. Furthermore, a detailed comparison with the holotype specimens of Brontopodus, Parabrontopodus and other sauropod ichnogenera that may provide evidence for a possible synonymy was not undertaken. Since the vast majority of known sauropod tracks lack anatomical details (Wright, 2005), their classification is often based solely on trackway parameters, most importantly trackway gauge. Diedrich (2011b) characterization of the gauge shown by the Barkhausen sauropod tracks, however, is contradictory. While the tracks were described as "wide-gauged" at various occasions ("[...] mainly wide-gauge trackway [...]" (p. 137); "[...] similar [...] wide-gauged trackways [...]" (p. 139); "Only narrow-gauged tracks, [...], are significantly different [...]" (p. 140)), they are declared "narrow-gauged" at others ("[...] completely identical manus/pes sets and narrow gauged trackways [...]" (p. 140); "[...] the trackways are all similar narrow gauged ones [...]" (p. 140)). Consequently, the comparisons of the Barkhausen sauropod tracks with other sauropod tracksites made by Diedrich (2011b) are flawed.

Diedrich (2011b) noted that "similar heteropod-shaped and wide-gauged trackways also described from the Upper Cretaceous (Cenomanian) of Croatia [...] have recently been assigned to Elephantopoides (Diedrich 2010a)" (p. 139), which later was cited as evidence for a stratigraphic range of Elephantopoides up to the "basal Late Cretaceous" (p. 140). However, in the reference list "Diedrich 2010a" is cited as an article in press, yet to be published in the Bulletin of the Tethys Geological Society under the title "Dinosaur megatracksites in carbonate intertidal flats and their possible producers in the Cenomanian/Turonian of the Northern Tethys-coastal migration zones between Afrika [sic] and Europe" (p. 154). An article with this or a similar title was, in July 2014, not traceable in any journal. Nevertheless, this article was cited by Diedrich (2011b) seven times at various occasions (pp. 139, 140, 141, 147). Later in the text, Diedrich (2011b) provided a contrary statement, referring the Croatian tracks not to Elephantopoides but to Brontopodus: "Only narrow-gauged tracks, such as those recently described from Croatia (Diedrich 2010a) and other sites in the Upper Cretaceous, are significantly different and must be differently named as Brontopodus." In this context, it also should be clarified that Brontopodus was defined to represent widegauged, and not narrow-gauged, trackways (Farlow et al., 1989; Lockley et al., 1994). 
Europasaurus is not a misidentified juvenile brachiosaur. Diedrich (2011b) also mentioned the sauropod finds from the Langenberg Quarry and claimed that "[...] a juvenile brachiosaur specimen was misidentified by its bone structure as being a "dwarf island species", for which a new dinosaur ichnogenus and species "Europasaurus holgeri" was established from bone histological studies by Sander et al. (2006)" (p. 152). He stated that "This was subsequently revised as a result of studies by Karl (2006) who showed it was a juvenile brachiosaur" (p. 152). Several errors of this statement must be corrected. First, Europasaurus holgeri was not established from "bone histological studies" but is solely based on morphological autapomorphies, which clearly show its distinctness from "brachiosaurs". Secondly, and for the same reason, Europasaurus was not erected as an "ichnogenus and species". Thirdly, Europasaurus holgeri was not established by Sander et al. (2006), but by Mateus et al. in Sander et al. (2006). Fourthly, Karl (2006) did not revise the dwarf hypothesis established by Sander et al. (2006). Karl (2006) did not cite Sander et al. (2006) and did not mention the possibility of the sauropod remains representing a dwarfed species. While referring the sauropod remains to Brachiosaurinae without further discussion, he suggested a juvenile status only for a single ulna. Thus, he did not necessarily contradict the dwarf hypothesis, which was based on histological samples from six individuals representing both juveniles and adults (Sander et al., 2006). The dwarf hypothesis was not questioned in any published peer-reviewed article.

Diedrich (2011b) also stated that "[...] large theropod bones, including jaws and teeth from the brachiosaur-bearing layers of the Upper Kimmeridgian of the Wiehengebirge and the Langenberg, also do not support the "dwarf theory"." (p. 152). It has to be pointed out that Europasaurus finds in the Langenberg Quarry are restricted to a specific layer approximately half a meter in thickness rather than several layers (Sander et al., 2006; Fischer, 1991). Evidence for an equivalent of this specific layer in the Wiehen Mountains was not provided. Other layers in the Langenberg Quarry reveal bones of larger dinosaurs as well as the large theropod footprints described herein, but are stratigraphically separated from the Europasaurus-bearing layer. As insular dwarfism can happen at an extremely fast pace within a few hundred generations (Evans et al., 2012), it is possible that Europasaurus was restricted to a narrow time interval.
Dryosaurus cannot qualify as a possible trackmaker of a tridactyl track from Bergkirchen. Diedrich (2011b) illustrated and interpreted a tridactyl footprint from the Bergkirchen site, which he referred to the ichnogenus Grallator. This ichnogenus represents the tracks of small to mediumsized theropods (Olsen et al., 1998). Diedrich (2011b) listed the ornithopod Dryosaurus as a possible trackmaker, but did not provide evidence for this suggestion. In fact, the interpretative drawing (figure 14, p. 145) provided by Diedrich (2011b) shows many characteristics commonly found in theropod tracks, including pointed claw impressions, a high length-to-width ratio, and a metatarsophalangeal pad behind digit impression IV, resulting in an asymmetrical "heel" (e.g., Thulborn, 1990). Diedrich (2011b) noted that "Digit II is the longest, and digit IV the shortest" (p. 145), evidently misidentifying digit II as digit IV, and vice versa. In figure $15 \mathrm{~b}$ (p. 146), the pedal skeleton of Dryosaurus was projected into the outline drawing of the footprint, again by erroneously labeling digit IV and digit II. In the "idealised trackway of Grallator isp." in figure 15c, the longest digit (in fact representing digit IV) is erroneously shown as the innermost, and the shortest digit (in fact digit II) as the outermost.

While referring the footprint only to Grallator isp. rather than to any ichnospecies in particular, Diedrich (2011b) nevertheless provided a diagnosis section, which apparently does not apply to the ichnogenus as a whole but only to this track. In that section, he reconstructed the phalangeal formula of the trackmaker based on the number of the digital pad impressions: "The phalanx formula resulting from the interphalangeal articulation impressions is: 3 (digit IV), 4 (digit III), 5 (digit II) [...]." (p. 145). Besides mistaking digit II for digit IV and digit IV for digit II, the phalangeal formula of the trackmaker probably cannot be reconstructed based on phalangeal pads alone (e.g., Thulborn, 1990). Furthermore, the footprint is poorly preserved and appears to be badly weathered (personal observation, JNL); thus the exact identification of the whole set of phalangeal pads might be an over-interpretation.

Finally, Diedrich (2011b) noted that a "lightweight bone construction similar to that of pterosaurs is characteristic of the Kimmeridgian ornithopod Dryosaurus sp. [...], which has [...] a worldwide distribution (cf. Galton 1980a, b)." (p. 145). Since postcranial skeletal pneumaticity is present in pterosaurs but absent in all ornithischians (Wedel, 2006), the bone construction cannot be directly compared with that of pterosaurs. A 
worldwide distribution of Dryosaurus is not suggested by Galton $(1980,1981)$, who only noted the occurrence in western North America and East Africa. In recent studies, the East African taxon often is placed into its own genus, Dysalotosaurus (Witzmann et al., 2008; Hübner and Rauhut, 2010). Comparing the footprint with typical Grallator tracks from Portugal, Diedrich (2011b) cited "unnamed 2002" (p. 145). In the reference list (p. 155), nothing more than a title and a weblink was provided; the weblink is not working and the source therefore untraceable.

Evidence for the referral of a tridactyl footprint from Bergkirchen to Camptosaurus is flawed. A single tridactyl pes footprint from the Bergkirchen site was referred by Diedrich (2011b) to ?/guanodontipus sp. Diedrich (2011b) envisaged Camptosaurus as a possible trackmaker based on the shape of the digits: "Digit IV has no hoof, is more slender and also shorter (see skeleton anatomy in figure 13), and hence the footprints differ from typical Iguanodon footprints as a result of this more slender and non-hoofed digit IV." (p. 144). Diedrich (2011b) concluded: "Following the reconstruction of the pedal anatomy, it appears that the trackmakers of these large footprints [...] have possibly been left by the large camptosaurid Camptosaurus [...]."

There are several problems with this interpretation. The only evidence suggesting the link of the footprint with Camptosaurus was provided through figure 13b (p. 144), which shows the fit of a skeletal reconstruction of an autopodium of Camptosaurus into the Bergkirchen footprint. However, although labeled as "Pes", the shown autopodium in fact is a manus skeleton (cf. Carpenter and Wilson, 2008). Thus, the alleged connection of the footprint with Camptosaurus is flawed in its fundamentals. This error was repeated in the text, where the camptosaurid pes anatomy was elaborated upon.

In this context, there are additional errors in figure 13 (Diedrich, 2011b) that need clarification. First, the manus skeleton (labeled as "Pes") shown in figure 13b lack a digital phalanx on digit III when compared with the reconstruction provided by Carpenter and Wilson (2008). Although the data source of figure $13 \mathrm{~b}$ was not specified by Diedrich (2011b), at least for figure 13a Carpenter and Wilson (2008) was cited as the source. Secondly, the "idealised reconstructed trackway based on Iguanodontipus trackways [...]" (figure 13c) is in error, showing the most slender digit impression as the innermost of the footprints. In the text and in figure $13 \mathrm{~b}$, this slender digit is labeled "IV" and was cor- related with the fourth digit of the manus skeleton of figure 13b (labeled as "Pes"). A trackway reconstruction including manus impressions was provided despite the fact that only one single footprint is known. This is serious, because it was also noted that the footprint probably represents a separate ichnospecies: "This footprint is therefore only attributed to this ichnogenus [Iguanodontipus] in a preliminary way and would at least represent a different ichnospecies from the Lower Cretaceous iguanodontid footprints." (p. 144).

Further errors occurring in the description of the footprint have to be pointed out as well. Diedrich (2011b) noted: "The heel impression is not convex, as in tridactyl theropod footprints, but on the contrary is U-shaped" (p. 144). However, in the interpretational drawing provided in figure 12, the footprint in fact is shown with a convex heel impression. Furthermore, it was claimed that "only digits II and III are present" (p. 144), although the presence of digit IV was indicated both in the interpretative drawing (figure 12) and elsewhere in the text. Last but not least, within the works cited to underline the alleged wide distribution of Camptosaurus, a popular science book (Holtz, 2007) cannot be regarded as a citeable source.

The presence of dinosaur genera well known from the North American Morrison Formation (Camarasaurus, Brachiosaurus, Allosaurus, Dryosaurus, Camptosaurus) in the Wiehen Mountains is not documented by skeletal finds. Diedrich (2011b) proposed dinosaur interchanges between Eurasia and North America (p. 129). Evidence was derived from the described track types referred to trackmaker genera which are not endemic to Europe. Skeletal remains stemming from the track localities were ascribed to the same genera; in all cases, this was seemingly based on subjective resemblance rather than on synapomorphies, and most of the illustrated material does not seem to be diagnostic at all.

For the sauropod tracks from Barkhausen and adjacent localities, Diedrich (2011b) considered Brachiosaurus as a probable trackmaker, stating that recent discoveries stem "most probably from this dinosaur genus (two teeth, one claw phalanx, and one femur head, and one giant lumbar vertebra centrum [...]" (p. 141). Furthermore, he noted that "other sauropods, including camarosaurids [sic] and apatosaurids, also appear to have been recently identified in northern Germany from single tooth and postcranial bone remains (bones from Nettelstedt, figure 19, 2-4)" (p. 141). However, figure 19, 2 (p. 151) is labeled "Large sauropod 
(?Brachiosaurus tooth cusp [...])", without mentioning camarasaurids or apatosaurids at all, while figure 19,3 is labeled "?Brachiosaurus or Camarasaurus", and figure 19, 4, labeled "large sauropod distal femur fragment", does not mention a specific type of sauropod. According to the figure and the figure caption, we assume that an unambiguous referral of the material to a specific sauropod taxon is not possible. Consequently, these fossils cannot be cited as evidence for the referral of sauropod tracks to specific trackmakers.

According to Diedrich (2011b), "Allosaurus sp. or Megalosaurus sp. might be the most likely trackmakers" (p. 143) of the theropod tracks, based on two teeth referred to these genera by the author (a "Serrulated [sic] theropod (?Allosaurus) tooth [...]" (figure 19, 6, p. 151) and a "Incomplete theropod (?Megalosaurus) tooth [...]" (figure 19, 6, p. 151)). Again, this evidence is not sufficient to claim the presence of these genera.

Underpinning the referral of an ornithopod footprint from Bergkirchen to Camptosaurus, Diedrich (2011b) stated "The possible ? Camptosaurus tooth from the Lower Kimmeridgian paleosol bed at Nettelstedt (see figure 19,1) supports this suggestion." However, figure 19, 1 is labeled "Large sauropod (?Camarosaurus [sic]) tooth cusp [...])" (figure 19,1, p. 151), and the Camptosaurus material is apparently not illustrated anywhere in the paper.

The referral of a Grallator footprint found in Bergkirchen to the ornithopod Dryosaurus also was suggested to be supported by skeletal material (Diedrich, 2011b): "A humerus fragment was also found in the Lower Kimmeridgian paleosol bed at Nettelstedt which appears to belong to Dryosaurus (see figure 19)" (p. 146). The only illustration in figure 19 that the above statement possibly refers to is labeled "medium-sized ornithopod dryosaurid (?Dryosaurus) radius [...])" (figure 19, 8); however, a humerus fragment is not illustrated anywhere in the paper. In the introduction, Diedrich (2011b) added to the confusion by noting "a dryosaurid ulna (?Dryosaurus sp.)" (p. 130) from Nettelstedt, without mentioning a humerus fragment or a radius. This ulna was not mentioned elsewhere in the paper.

Megatracksites do not support the hypothesis of faunal interchanges between America and Eurasia. Diedrich (2011b) aimed to provide a reinterpretation of the Barkhausen tracksite as well as a description and interpretation of two new tracksites from the Wiehen Mountains, the sites of Nettelstedt and Bergkirchen. Based on these three Wiehen Mountain tracksites, a megatracksite north of the Rhenisch Massiv was proposed. Similar extensive megatracksites "between Jurassic islands in central [sic] Europe" (p. 129) were suggested to have "formed periodic bridges between the islands, allowing dinosaur interchanges and migrations between America and Eurasia, which may help to explain the much broader palaeobiogeographic distributions of dinosaur species during the Late Jurassic" (p. 129). This conclusion is problematic, because the megatracksites as pointed out by Diedrich (2011b) are coastal megatracksites which, according to the provided paleogeographic map (figure 18, p. 150), are lining the coastlines but do not extend between islands. Evidence for periodical bridges between islands, however, was not provided. The only exception is the Swiss Jura carbonate platform, which probably did connect the Massif Central with the Rhenish Massif. The possible role of the Swiss Jura platform as a migration route was already noted and discussed by Meyer (1993). The idea that land bridges have allowed faunal interchange between North America and Eurasia was presented by Diedrich (2011b) as a fact, but again no evidence was provided other than the suggested similarity of the dinosaur fauna of both continents. Although Diedrich (2011b) claimed to have compared the tracks from the Wiehen Mountains with "all other known European localities" (p. 129), a quick literature review shows that many well described sites have been omitted, including all sites reported from France (LangeBadré et al., 1996; Le Lœuff et al., 2006), Croatia (Mezga et al., 2007), and Poland (Gierliński et al., 2009; Gierliński, 2009; Gierliński et al., 2001; Gierliński and Niedźwiedzki, 2002; Gierliński and Sabath, 2002). Under the heading "Ichnotaxonomic problems and intertidal site comparisons" ( $p$. 147), Diedrich (2011b) exclusively compared the ichnofauna of the Wiehen Mountains with the Swiss Chevenez Combe Ronde site. In this section, he also indicated that "many ornithopod tracks (Carmelopodus)" (p. 147) were referred by Marty (2008) to an ornithopod trackmaker. In fact, Marty (2008) referred these tracks to a theropod trackmaker.

The three tracksites from the Wiehen Mountains were suggested to form a megatracksite within the Sand/Tonkomplex Member of the Süntel Formation, which is late Kimmeridgian in stratigraphic age (Diedrich, 2009, 2011b). As incorrectly noted by Diedrich (2011b), the Barkhausen site was dated to the early Kimmeridgian by Lockley and Meyer (2000). This information, however, was not given by these authors. From the Nettelstedt 
locality, the author reported one single manus/pes set of Elephantopoides isp. still present in the wall of an inactive quarry. Although a figure caption reads "Possible manus/pes set" (figure 4), this occurrence was presented as unquestionable in the remainder of the article.

\section{CONCLUSIONS}

The loss of specimens is a persistent problem in paleontology. This holds true especially for footprints, which are often left in situ because an excavation is not desirable or realizable, and therefore are exposed to weathering (Bennett et al., 2013). When a specimen is removed from its stratigraphical and paleobiological context during excavation, the loss of important information is a likely risk, especially when excavations are insufficiently documented (i.e., emergency excavations). In such cases, historical photogrammetry, a method recently introduced in paleontology by Falkingham et al. (2014), may allow one to regain data that otherwise would be lost. In our case, historical photogrammetry provided a wealth of information on both destroyed and excavated footprints and their exact location and orientation at the tracksite. Possible footprints noted by the excavators were validated and even an additional trackway was identified. Precise measurements were possible due to scale provided by meter sticks on the archival photographs. One footprint (DFMMh/FV 647) was digitally reconstructed as it was in situ based on only three archival photographs.

Several lines of evidence (the sedimentary conditions, the preservation of a hallux trace in footprint 7 , and the strongly inclined digit impression of DFMMh/FV 648) suggest that the Langenberg tracks represent true tracks rather than undertracks. As revealed by both the historical photogrammetry and the examination of the excavated specimens the Langenberg tracksite contains footprints of different preservation types. Deep tracks with elongated, posteriorly tapering heel impressions, weak and irregular digit impressions, and, in one case, a hallux impression, were found alongside well defined footprints, which may preserve claw impressions and, in one case (DFMMh/FV 648), even a strongly inclined digit impression IV. The latter feature records the movements of the trackmaker's foot. These differences suggest different substrate properties at different times during the genesis of the tracksite rather than different trackmaker taxa. Most probably, the sediment maintained a high water content when the deep tracks were left, and was moist (but not dry) when the well-defined footprints were left. All tracks can be identified as functionally tridactyl, and most could be assigned to theropod dinosaurs, whereas sauropod tracks could not be identified. The excavated footprints, albeit varying in size from $36 \mathrm{~cm}$ to $54 \mathrm{~cm}$, cannot be unequivocally ascribed to separate trackmaker species. The two largest footprints are proportionally wider, which may suggest that at least two different trackmaker species were present at the site, although an ontogenetic explanation of these differences cannot be ruled out.

The two largest and best preserved footprints from the Langenberg are very similar in terms of footprint dimensions to roughly contemporaneous tracks from Barkhausen, but different from many other Late Jurassic tracks assembled under the name Megalosauripus because of their greater width. Although the width-to-length ratio regularly is employed to discriminate between ornithopod and theropod trackmakers (e.g., Romilio and Salisbury, 2010; Romilio and Salisbury, 2014; Mateus and Milàn, 2008), the great width of the two largest Langenberg footprints indicates that this is not an infallible criterion. The different preservation types recorded in the Langenberg tracksite emphasize that many features of tridactyl tracks are induced or influenced by substrate properties rather than the anatomy of the trackmaker's foot (e.g., Gatesy et al., 1999; Gatesy, 2003). Such features, e.g., the presence of a hallux impression or the morphology of the digit and heel impressions in deep tracks, nevertheless are found in diagnoses of ichnogenera such as Bueckeburgichnus and Tyrannosauripus. This underscores the need for a critical revision of the ichnotaxonomy of the track record of large theropods.

\section{ACKNOWLEDGMENTS}

This work is based on the M.Sc. Thesis of one of us (JNL). First of all we thank $\mathrm{H}$. Lüdtke for discovering the tracksite and providing his archival photographs. The "Rohstoffbetriebe Oker $\mathrm{GmbH}$ and Co." is acknowledged for access to the quarry and logistic help. We are grateful to editor A. Bush and two anonymous reviewers for their constructive comments and to $\mathrm{H}$. Mallison for a critical review of an early version of the manuscript. Furthermore we thank $S$. Läbe for discussions about the photogrammetric procedure, $\mathrm{O}$. Gerke for information on the theropod teeth of bed 83, D. Thies for information on the stratigraphy of the Langenberg section, and $O$. Dülfer for technical advice. We are very grateful to the Volkswagen Foundation for generously funding the Europasaurus-Project in 
the "Research in Museums" program. Last but not least, we would like to thank all the volunteers and preparators for their work on the Langenberg material.

\section{REFERENCES}

Agisoft LLC. 2014. Agisoft PhotoScan User Manual: Professional Edition, Version 1.0. Downloaded 12 December 2014. www.agisoft.com/pdf/photoscanpro_1_0_en.pdf

Alexander, R.M. 1976. Estimates of speeds of dinosaurs. Nature, 261:129-130. doi:10.1038/261129a0.

Baird, D. 1957. Triassic reptile footprint faunules from Milford, New Jersey. Bulletin of the Museum of Comparative Zoology, 117:449-520.

Bakker, R.T. 1996. The real Jurassic Park: dinosaurs and habitats at Como Bluff, Wyoming. In Morales, M (ed.), The Continental Jurassic. Museum of Northern Arizona Bulletin, 60:35-49.

Bennett, M.R., Falkingham, P., Morse, S.A., Bates, K., and Crompton, R.H. 2013. Preserving the impossible: Conservation of soft- sediment hominin footprint sites and strategies for three-dimensional digital data capture. PLOS ONE, 8:e60755.

Carballido, J.L. and Sander, P.M. 2013. Postcranial axial skeleton of Europasaurus holgeri (Dinosauria, Sauropoda) from the Upper Jurassic of Germany: implications for sauropod ontogeny and phylogenetic relationships of basal Macronaria. Journal of Systematic Palaeontology, 12:335-387.

Cariou, E., Olivier, N., Pittet, B., Mazin, J.-M., and Hantzpergue, P. 2014. Dinosaur track record on a shallow carbonate-dominated ramp (Loulle section, Late Jurassic, French Jura). Facies, 60:229-253.

Carpenter, K. and Wilson, Y. 2008. A new species of Camptosaurus (Ornithopoda: Dinosauria) from the Morrison Formation (Upper Jurassic) of Dinosaur National Monument, Utah, and a biomechanical analysis of its forelimb. Annals of the Carnegie Museum, 76:227-263.

Castanera, D., Pascual, C., Razzolini, N.L., Vila, B., Barco, J.L., and Canudo, J.I. 2013. Discriminating between medium-sized tridactyl trackmakers: Tracking ornithopod tracks in the base of the Cretaceous (Berriasian, Spain). PLoS ONE, 8:e81830.

Chandler, J.H. and Clark, J.S. 1992. The archival photogrammetric technique: further application and development. The Photogrammetric Record, 14:241-247.

Chandler, J.H. and Cooper, M.a.R. 1989. The extraction of positional data from historical photographs and their application to geomorphology. The Photogrammetric Record, 13:69-78.

Colbert, E.H. and Merrilees, D. 1967. Cretaceous dinosaur footprints from Western Australia. Journal of the Royal Society of Western Australia, 50:21-25.
Diedrich, C. 2009. Stratigraphy, fauna, palaeoenvironment and palaeocology of the Stollenbank Member (Süntel Formation, mutabilis/eudoxus zonal boundary, KIM 4, Upper Kimmeridgian) of NW Germany. Neues Jahrbuch für Geologie und Paläontologie Abhandlungen, 252:327-359.

Diedrich, C. 2011a. The shallow marine placodont Cyamodus of the Central European Germanic Basin: its evolution, paleobiogeography and paleoecology. Historical Biology, 23:391-409.

Diedrich, C. 2011b. Upper Jurassic tidal flat megatracksites of Germany-coastal dinosaur migration highways between European islands, and a review of the dinosaur footprints. Palaeobiodiversity and Palaeoenvironments, 91:129-155.

Evans, A.R., Jones, D., Boyer, A.G., Brown, J.H., Costa, D.P., Ernest, S.K.M., Fitzgerald, E.M.G., Fortelius, M., Gittleman, J.L., Hamilton, M.J., Harding, L.E., Lintulaakso, K., Lyons, S.K., Okie, J.G., Saarinen, J.J., Sibly, R.M., Smith, F.A., Stephens, P.R., Theodor, J.M., and Uhen, M.D. 2012. The maximum rate of mammal evolution. Proceedings of the National Academy of Sciences, 109:4187-4190.

Falkingham, P.L. 2012. Acquisition of high resolution three-dimensional models using free, open-source, photogrammetric software. Palaeontologia Electronica, 15.1.1T:15p; http://palaeo-electronica.org/content/issue1-2012technical-articles/92-3dphotogrammetry

Falkingham, P.L. 2014. Interpreting ecology and behaviour from the vertebrate fossil track record. Journal of Zoology, 292:222-228.

Falkingham, P.L., Bates, K.T., and Farlow, J.O. 2014. Historical photogrammetry: Bird's Paluxy River dinosaur chase sequence digitally reconstructed as it was prior to excavation 70 years ago. PLOS ONE, 9:e93247.

Falkingham, P.L. and Gatesy, S.M. 2014. The birth of a dinosaur footprint: Subsurface 3D motion reconstruction and discrete element simulation reveal track ontogeny. Proceedings of the National Academy of Sciences, 111:18279-18284.

Farlow, J.O., Bonnan, M.E., Rainforth, E.C., Benson, J., and Shearer, K. 2012. Emus, alligators, and Eubrontes: assessing intraspecific and interspecific variability in foot and footprint shape, p. 21. In Richter, A. and Reich, M. (eds.), Dinosaur Tracks 2011, An International Symposium, Obernkirchen, April 14-17, 2011. Abstracts Volume and Field Guide to Excursions. Universitätsdrucke Göttingen.

Farlow, J.O., Gatesy, S.M., Holtz, T.R., Hutchinson, J.R., and Robinson, J.M. 2000. Theropod locomotion. American Zoologist, 40:640-663. 
Farlow, J.O., Holtz, T.R., Worthy, T.H., and Chapman, R.E. 2013. Feet of the fierce (and not-so-fierce): pedal proportions in large theropods, other non-avian dinosaurs and large ground birds, p. 89-132. In Parrish, J.M., Molnar, R.E., Currie, P.J., and Koppelhus, E.B. (eds.), Tyrannosaurid Paleobiology. Indiana University Press, Bloomington.

Farlow, J.O., Pittman, J.G., and Hawthorne, J.M. 1989. Brontopodus birdi, Lower Cretaceous sauropod footprints from the US Gulf coastal plain, p. 371-394. In Gillette, D.D. and Lockley, M.G. (eds.), Dinosaur Tracks and Traces. Cambridge University Press.

Fiorillo, A.R. and Adams, T.L. 2012. A therizinosaur track from the lower Cantwell Formation (Upper Cretaceous) of Denali National Park, Alaska. Palaios, 27:395-400.

Fischer, R. 1991. Die Oberjura-Schichtfolge vom Langenberg bei Oker. Arbeitskreis Paläontologie Hannover, 19:21-36.

Fox, A.J. and Cooper, A.P.R. 1998. Climate-change indicators from archival aerial photography of the Antarctic Peninsula. Annals of Glaciology, 27:636-642.

Galton, P.M. 1980. Dryosaurus and Camptosaurus, intercontinental genera of Upper Jurassic ornithopod dinosaurs. Mémoires de la Société Géologique de France, 139:103-108.

Galton, P.M. 1981. Dryosaurus, a hypsilophodontid dinosaur from the Upper Jurassic of North America and Africa - postcranial skeleton. Paläontologische Zeitschrift, 55:271-312.

Gatesy, S.M. 2003. Direct and indirect track features: what sediment did a dinosaur touch? Ichnos, 10:9198.

Gatesy, S.M., Middleton, K.M., Jenkins, F.A., and Shubin, N.H. 1999. Three-dimensional preservation of foot movements in Triassic theropod dinosaurs. Nature, 399:141-144. doi:10.1038/20167.

Gerke, O. and Wings, O. 2014. Characters versus morphometrics: a case study with isolated theropod teeth from the Late Jurassic of Lower Saxony, Germany, reveals an astonishing diversity of theropod taxa. Journal of Vertebrate Paleontology, Program and Abstracts, 137.

Gierliński, G. 2009. A preliminary report on new dinosaur tracks in the Triassic, Jurassic and Cretaceous of Poland. Actas de las IV Jornadas Internacionales sobre Paleontologìa de Dinosaurios y su Entorno Salas de los Infantes, Burgos, 75-90.

Gierliński, G., Gaździcka, E., Niedzwiedzki, G., and Pieńkowski, G. 2001. New ornithischian footprints in the Jurassic of Poland. Geological Quarterly, 45:205210.

Gierliński, G. and Niedźwiedzki, G. 2002. Dinosaur footprints from the Upper Jurassic of Blaziny, Poland. Geological Quarterly, 46:463-465.

Gierliński, G., Niedzwiedzki, G., and Nowacki, P. 2009. Small theropod and ornithopod footprints in the Late Jurassic of Poland. Acta Geologica Polonica, 59:221-234.
Gierliński, G. and Sabath, K. 2002. A probable stegosaurian track from the Late Jurassic of Poland. Acta Palaeontologica Polonica, 47:561-564.

Hardenbol, J., Thierry, J., Farley, M.B., Jacquin, T., De Graciansky, P.-C., and Vail, P.R. 1998. Mesozoic and Cenozoic Sequence Chronostratigraphic Framework of European Basins, p. 3-13. In De Graciansky, P.C., Hardenbol, J., Jacquin, T., and Vail, P.R. (eds.), Mesozoic and cenozoic sequence stratigraphy of European Basins, SEPM Special Publication 60.

Hartman, S. 2013. Skeletal reconstruction of Allosaurus sp. (MOR 693). Accessed 12 December 2014 and used with permission. http://www.skeletaldrawing.com/theropods/allosaurus-sp

Henderson, D. 2003. Footprints, trackways, and hip heights of bipedal dinosaurs-testing hip height predictions with computer models. Ichnos, 10:99-114.

Holz, T.R. 2007. Dinosaurs: The Most Complete, Up-toDate Encyclopedia for Dinosaur Lovers of All Ages. Random House Books for Young Readers.

Hübner, T.R. and Rauhut, O.W.M. 2010. A juvenile skull of Dysalotosaurus lettowvorbecki (Ornithischia: Iguanodontia), and implications for cranial ontogeny, phylogeny, and taxonomy in ornithopod dinosaurs. Zoological Journal of the Linnean Society, 160:366396.

Jackson, S.J., Whyte, M.A., and Romano, M. 2010. Range of experimental dinosaur (Hypsilophodon foxii) footprints due to variation in sand consistency: How wet was the track? Ichnos, 17:197-214.

Kaever, M. and Lapparent, A.F. de. 1974. Les traces de pas de dinosaures du Jurassique de Barkhausen (Basse Saxe, Allemagne). Bulletin de la Sociietie Gieologique de France, 16:516-525.

Karl, H.-V. 2006. Über fossile Osteoblasten in Sauropodenknochen - Der Einsatz der Mikroskopie in der Wirbeltierpaläontologie. Mikrokosmos, 95:199_ 201.

Kuhn, O. 1958. Die Fährten der vorzeitlichen Amphibien und Reptilien. Verlaghaus Meisenbach KG, Bamberg.

Lange-Badrìe, B., Dutrieux, M., Feyt, J., and Maury, G. 1996. Diecouverte d'empreintes de pas de dinosaures dans le Jurassique supierieur des Causses du Quercy (Lot, France). Comptes Rendus de l'Acadiemie des Sciences. Sierie 2. Sciences de la terre et des planietes, 323:89-96.

Le Lœuff, J., Gourrat, C., Landry, P., Hautier, L., Liard, R., Souillat, C., Buffetaut, E., and Enay, R. 2006. A Late Jurassic sauropod tracksite from southern Jura (France). Comptes Rendus Palevol, 5:705-709.

Leonardi, G. 1987. Discussion of the terms and methods, p. 43-51. In Leonardi (ed.), Glossary and Manual of Tetrapod Footprint Palaeoichnology. Publicação do Departemento Nacional da Produção Mineral Brasil, Brasília.

Lockley, M.G. 1991. Tracking Dinosaurs. Cambridge University Press, Cambridge. 
Lockley, M.G. 2000. An amended description of the theropod footprint Bueckeburgichnus maximus Kuhn 1958, and its bearing on the megalosaur tracks debate. Ichnos, 7:217-225.

Lockley, M.G. 2010. New perspectives on morphological variation in tridactyl footprints: clues to widespread convergence in developmental dynamics. Geological Quarterly, 53:415-432.

Lockley, M.G., Farlow, J.O., and Meyer, C.A. 1994. Brontopodus and Parabrontopodus ichnogen. nov. and the significance of wide-and narrow-gauge sauropod trackways. GAIA, 10:135-145.

Lockley, M.G. and Hunt, A.P. 1994. A track of the giant theropod dinosaur Tyrannosaurus from close to the Cretaceous/Tertiary boundary, northern New Mexico. Ichnos, 3:213-218.

Lockley, M.G. and Meyer, C. 2000. Dinosaur tracks and other fossil footprints of Europe. Columbia University Press, New York.

Lockley, M.G., Meyer, C.A., and Moratalla, J.J. 1998a. Therangospodus: trackway evidence for the widespread distribution of a Late Jurassic theropod with well-padded feet. GAIA, 15:339-353.

Lockley, M.G., Meyer, C.A., and Dos Santos, V.F. 1996. Megalosauripus, Megalosauropus and the concept of megalosaur footprints. In Morales, M (ed.), The continental Jurassic. Museum of Northern Arizona Bulletin, 60:113-118.

Lockley, M.G., Meyer, C., and Dos Santos, V.F. 1998b. Megalosauripus and the problematic concept of megalosaur footprints. GAIA, 15:313-337.

Mallison, $H$. and Wings, O. 2014. Photogrammetry in paleontology - A practical guide. Journal of Paleontological Techniques, 12:1-31.

Marpmann, J.S., Carballido, J.L., Sander, P.M., and Knötschke, N. 2015. Cranial anatomy of the Late Jurassic dwarf sauropod Europasaurus holgeri (Dinosauria, Camarasauromorpha): ontogenetic changes and size dimorphism. Journal of Systematic Palaeontology, 13:221-263.

Marty, D. 2008. Sedimentology, taphonomy, and ichnology of Late Jurassic dinosaur tracks from the Jura carbonate platform (Chevenez-Combe Ronde tracksite, NW Switzerland): insights into the tidal-flat palaeoenvironment and dinosaur diversity, locomotion, and palaeoecology. GeoFocus, 21:1-278.

Marty, D. and Billon-Bruyat, J.-P. 2009. Field-trip to the excavations in the Late Jurassic along the future Transjurane highway near Porrentruy (Canton Jura, NW Switzerland): dinosaur tracks, marine vertebrates and invertebrates, p. 95-129. In Billon-Bruyat, J.-P., Marty, D., Costeur, L., Meyer, C.A., and Thüring, B. (eds.), 5th International Symposium on Lithographic Limestone and Plattenkalk. Abstracts and Field Guides.

Marty, D., Hug, W., Iberg, A., Cavin, L., Meyer, C., and Lockley, M. 2003. Preliminary report on the Courtedoux dinosaur tracksite from the Kimmeridgian of Switzerland. Ichnos, 10:209-219.
Marty, D., Meyer, C.A., Paratte, G., and Gattin, M. 2013. Overview on dinosaur tracksites in the Swiss and French Jura Mountains, p. 23-26. In Fernández-Baldor, F.T. and Huerta, P. (eds.), VI Jornadas Internacionales sobre Paleontología de Dinosaurios y su Entorno. Salas de los Infantes, Burgos.

Marty, D., Strasser, A., and Meyer, C.A. 2009. Formation and taphonomy of human footprints in microbial mats of present-day tidal-flat environments: implications for the study of fossil footprints. Ichnos, 16:127-142.

Mateus, O. and Milàn, J. 2008. Ichnological evidence for giant ornithopod dinosaurs in the Upper Jurassic Lourinha Formation, Portugal. Oryctos, 8:47-52.

Matthews, N.A. 2008. Aerial and close-range photogrammetric technology: Providing resource documentation, interpretation, and preservation. Technical Note 428. U.S. Department of the Interior, Bureau of Land Management, National Operations Center, Denver, Colorado.

Matthews, N.A. and Breithaupt, B.H. 2001. Close-range Photogrammetric Experiments at Dinosaur Ridge. The Mountain Geologist, 38:147-153.

Meyer, C.A. 1993. A sauropod dinosaur megatracksite from the Late Jurassic of northern Switzerland. Ichnos, 3:29-38.

Meyer, C.A. and Hauser, M. 1994. New sauropod and theropod tracksites from the Upper Jurassic megatracksite of Northern Switzerland. GAIA, 10:49-55.

Mezga, A., Tešović, B.C., and Bajraktarević, Z. 2007. First record of dinosaurs in the Late Jurassic of the Adriatic-Dinaridic Carbonate Platform (Croatia). Palaios, 22:188-199.

Milàn, J. 2006. Variations in the morphology of emu (Dromaius novaehollandiae) tracks reflecting differences in walking pattern and substrate consistency: ichnotaxonomic implications. Palaeontology, 49:405-420.

Milàn, J. and Bromley, R.G. 2007. The impact of sediment consistency on track and undertrack morphology: experiments with emu tracks in layered cement. Ichnos, 15:19-27.

Moratalla, J.J., Sanz, J.L., and Jimenez, S. 1988. Multivariate analysis on Lower Cretaceous dinosaur footprints: discrimination between ornithopods and theropods. Geobios, 21:395-408.

Nopsca, F.B. 1923. Die Familien der Reptilien. Fortschritte der Geologie und Paläontologie, 129147.

Olsen, P.E., Smith, J.B., and McDonald, N.G. 1998. Type material of the type species of the classic theropod footprint genera Eubrontes, Anchisauripus, and Grallator (Early Jurassic, Hartford and Deerfield basins, Connecticut and Massachusetts, USA). Journal of Vertebrate Paleontology, 18:586-601.

Pape, H. 1970. Die Malmschichtfolge vom Langenberg bei Oker (nördl. Harzvorland). Mitteilungen aus dem Geologischen Institut der Technischen Universität Hannover, 9:41-134. 
Rau, J., Chen, N.-Y., and Chen, L.-C. 2002. True orthophoto generation of built-up areas using multi-view images. Photogrammetric Engineering and Remote Sensing, 68:581-588.

Rainforth, E.C. and Manzella, M. 2007. Estimating speeds of dinosaurs from trackways: a re-evaluation of assumptions. Contributions to the Paleontology of New Jersey (II): Field Guide and Proceedings, Geological Association of New Jersey 24th Annual Conference and Field Trip, 41-48.

Romilio, A. and Salisbury, S.W. 2010. A reassessment of large theropod dinosaur tracks from the mid-Cretaceous (late Albian-Cenomanian) Winton Formation of Lark Quarry, central-western Queensland, Australia: A case for mistaken identity. Cretaceous Research, 32:135-142.

Romilio, A. and Salisbury, S.W. 2014. Large dinosaurian tracks from the Upper Cretaceous (CenomanianTuronian) portion of the Winton Formation, Lark Quarry, central-western Queensland, Australia: 3D photogrammetric analysis renders the "stampede trigger" scenario unlikely. Cretaceous Research, 51:186-207.

Sander, P.M., Mateus, O., Laven, T., and Knötschke, N. 2006. Bone histology indicates insular dwarfism in a new Late Jurassic sauropod dinosaur. Nature, 441:739-741.

Scheyer, T.M., Neenan, J.M., Renesto, S., Saller, F., Hagdorn, H., Furrer, H., Rieppel, O., and Tintori, A. 2012. Revised paleoecology of placodonts - with a comment on "The shallow marine placodont Cyamodus of the central European Germanic Basin: its evolution, paleobiogeography and paleoecology" by C.G. Diedrich (Historical Biology, iFirst article, 2011, 1-19, doi: 10.1080/08912963.2011.575938). Historical Biology, 24:257-267.

Schweigert, G. 1999. Neue biostratigraphische Grundlagen zur Datierung des nordwestdeutschen höheren Malm. Osnabrücker Naturwissenschaftliche Mitteilungen, 25:25-40.

Thies, D. and Mudroch, A. 1996. Actinopterygian teeth from the Late Jurassic (Kimmeridgian) of N Germany. Mesozoic Fishes-Systematics and Paleoecology, Dr. Friedrich Pfeil Verlag, München, 105-114.

Thies, D., Mudroch, A., and Turner, S. 2007. The potential of vertebrate microfossils for marine to nonmarine correlation in the Late Jurassic. Progress in Natural Science, 17:655-663.
Thulborn, R.A. 1990. Dinosaur tracks. Chapman and Hall, London.

Thulborn, R.A. 2001. History and nomenclature of the theropod dinosaur tracks Bueckeburgichnus and Megalosauripus. Ichnos, 8:207-222.

Thulborn, R.A. 2013. Lark Quarry revisited: a critique of methods used to identify a large dinosaurian trackmaker in the Winton Formation (Albian-Cenomanian), western Queensland, Australia. Alcheringa, $37: 312-330$.

Tintori, A. 2011. Comment on "The vertebrates of the Anisian/Ladinian boundary (Middle Triassic) from Bissendorf (NW Germany) and their contribution to the anatomy, palaeoecology, and palaeobiogeography of the Germanic Basin reptiles" by C. Diedrich (Palaeogeography, Palaeoclimatology, Palaeoecology 273 (2009) 1-16). Palaeogeography, Palaeoclimatology, Palaeoecology, 300:205-207.

Wedel, M.J. 2006. Origin of postcranial skeletal pneumaticity in dinosaurs. Integrative Zoology, 1:80-85.

Wiedemann, A., Hemmleb, M., and Albertz, J. 2000. Reconstruction of historical buildings based on images from the Meydenbauer archives. International Archives of Photogrammetry and Remote Sensing, 33:887-893.

Wings, O., Schellhorn, R., Mallison, H., Thuy, B., Wu, W., and Sun, G. 2007. The first dinosaur tracksite from Xinjiang, NW China (Middle Jurassic Sanjianfang Formation, Turpan Basin)-a preliminary report. Global Geology, 10:113-129.

Witzmann, F., Asbach, P., Remes, K., Hampe, O., Hilger, A., and Paulke, A. 2008. Vertebral pathology in an ornithopod dinosaur: A hemivertebra in Dysalotosaurus lettowvorbecki from the Jurassic of Tanzania. The Anatomical Record: Advances in Integrative Anatomy and Evolutionary Biology, 291:1149-1155.

Wright, J.L. 2005. Steps in understanding sauropod biology, p. 252-285. In Rogers, C.C. and Wilson, J. (eds.), The Sauropods: Evolution and Paleobiology. Oakland, California.

Zihrul, B. 1990. Mikrobiostratigraphie, Palökologie und Mikropaläontologie in Gesteinen des Unteren und Mittleren Malm am Langenberg bei Goslar/Oker. Ph.D. thesis, Institut für Geologie und Paläontologie der Technischen Universität Clausthal. 


\section{APPENDIX 1.}

Photograph of a polished cross section of the cast of a digit impression, revealing a gastropod rich biomicrite.

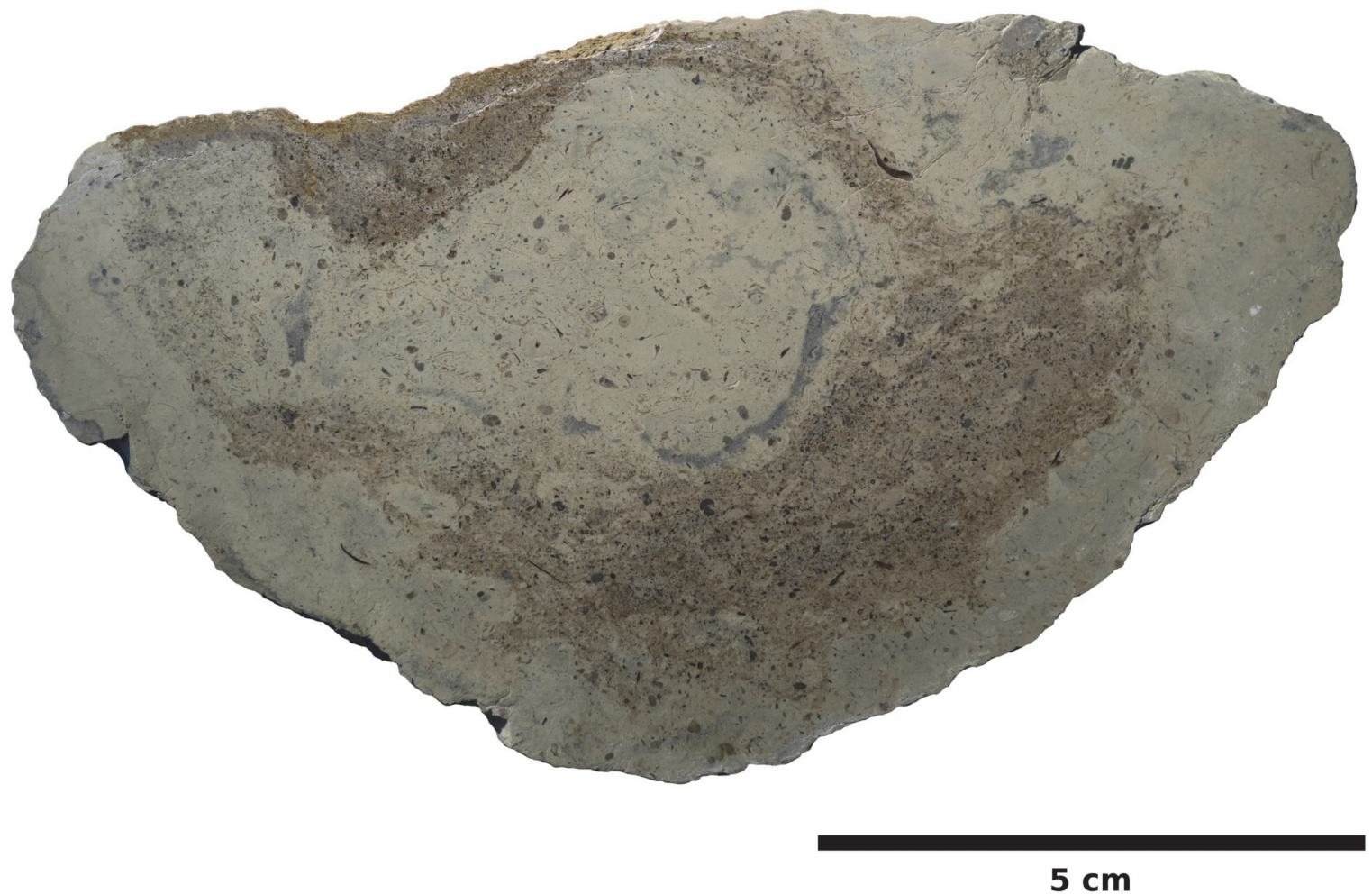




\section{APPENDIX 2.}

Three-dimensional model of the original Langenberg tracksite, based on archival photographs (taken by Nils Knötschke and Holger Lüdtke, 2003). Data is provided as a Adobe 3D-pdf and a PLY file with accompanying texture file. For all appendixes see online: palaeo-electronica.org/content/2015/1166-langenbergtracks

\section{APPENDIX 3.}

Three-dimensional photogrammetric model of DFMMh/FV 644. Data is provided as a Adobe 3D-pdf and a PLY file with accompanying texture file. For all appendixes see online: palaeo-electronica.org/content/ 2015/1166-langenberg-tracks

\section{APPENDIX 4.}

Three-dimensional photogrammetric model of DFMMh/FV 645. Data is provided as a Adobe 3D-pdf and a PLY file with accompanying texture file. For all appendixes see online: palaeo-electronica.org/content/ 2015/1166-langenberg-tracks

\section{APPENDIX 5.}

Three-dimensional photogrammetric model of DFMMh/FV 646. Data is provided as a Adobe 3D-pdf and a PLY file with accompanying texture file. For all appendixes see online: palaeo-electronica.org/content/ 2015/1166-langenberg-tracks

\section{APPENDIX 6.}

Three-dimensional photogrammetric model of DFMMh/FV 647. Data is provided as a Adobe 3D-pdf and a PLY file with accompanying texture file. For all appendixes see online: palaeo-electronica.org/content/ 2015/1166-langenberg-tracks

\section{APPENDIX 7.}

Three-dimensional photogrammetric model of DFMMh/FV 648. Data is provided as a Adobe 3D-pdf and a PLY file with accompanying texture file. For all appendixes see online: palaeo-electronica.org/content/ 2015/1166-langenberg-tracks

\section{APPENDIX 8.}

Three-dimensional photogrammetric model of DFMMh/FV 647 in situ, based on three archival photographs (taken by Nils Knötschke and Holger Lüdtke, 2003). Data is provided as a Adobe 3D-pdf and a PLY file with accompanying texture file. For all appendixes see online: palaeo-electronica.org/content/2015/ 1166-langenberg-tracks 